\title{
Transurethral radiofrequency collagen denaturation for the treatment of women with urinary incontinence (Review)
}

\author{
Kang D, Han J, Neuberger MM, Moy ML, Wallace SA, Alonso-Coello P, Dahm P
}

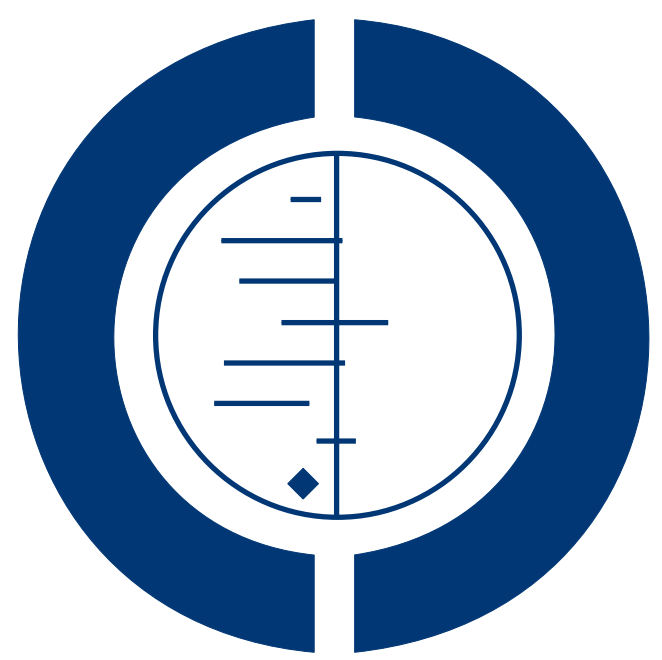

\section{THE COCHRANE COLLABORATION $^{\circledR}$}

This is a reprint of a Cochrane review, prepared and maintained by The Cochrane Collaboration and published in The Cochrane Library 2015, Issue 3

http://www.thecochranelibrary.com

\section{WILEY}

Transurethral radiofrequency collagen denaturation for the treatment of women with urinary incontinence (Review)

Copyright @ 2015 The Cochrane Collaboration. Published by John Wiley \& Sons, Ltd. 
TABLE OF CONTENTS

HEADER

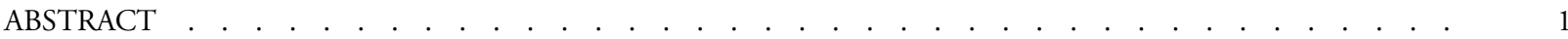

PLAIN LANGUAGE SUMMARY . . . . . . . . . . . . . . . . . . . . . . . . . . . . . . . . . . . .

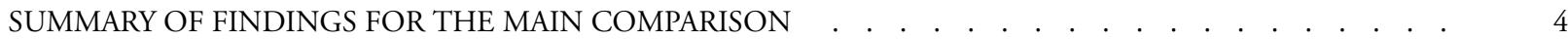

BACKGROUND . . . . . . . . . . . . . . . . . . . . . . . . . . . . . . . . . . . . . 6

OBJECTIVES . . . . . . . . . . . . . . . . . . . . . . . . . . . . . . . . . . . . . . . . . . . . . . . . . .

METHODS . . . . . . . . . . . . . . . . . . . . . . . . . . . . . . . . . . . . . . 8

RESULTS . . . . . . . . . . . . . . . . . . . . . . . . . . . . . . . . . . . . . . . 11

Figure 1. . . . . . . . . . . . . . . . . . . . . . . . . . . . . . . . . . . . .

Figure 2. . . . . . . . . . . . . . . . . . . . . . . . . . . . . . . . . . . . . . 14

Figure 3. . . . . . . . . . . . . . . . . . . . . . . . . . . . . . . . . . . . . . 15

Figure $4 . \quad$. . . . . . . . . . . . . . . . . . . . . . . . . . . . . . . . . . . . . 16

Figure 5. . . . . . . . . . . . . . . . . . . . . . . . . . . . . . . . . . . . . . 16

Figure 6. . . . . . . . . . . . . . . . . . . . . . . . . . . . . . . . . . . . . . 17

DISCUSSION . . . . . . . . . . . . . . . . . . . . . . . . . . . . . . . . . . . . . 18

AUTHORS' CONCLUSIONS . . . . . . . . . . . . . . . . . . . . . . . . . . . . . . . . . . . . . . 19

ACKNOWLEDGEMENTS . . . . . . . . . . . . . . . . . . . . . . . . . . . . . . . . . . . . . . . . .

REFERENCES . . . . . . . . . . . . . . . . . . . . . . . . . . . . . . . . . . . . . . 19

CHARACTERISTICS OF STUDIES . . . . . . . . . . . . . . . . . . . . . . . . . . . . . . . . . . . . . . .

DATA AND ANALYSES . . . . . . . . . . . . . . . . . . . . . . . . . . . . . . . . . . . . . . . . . . . . . . . . . . .

Analysis 1.1. Comparison 1 Transurethral radiofrequency collagen denaturation versus no treatment/sham treatment,

Outcome 1 Serious adverse events.

Analysis 1.2. Comparison 1 Transurethral radiofrequency collagen denaturation versus no treatment/sham treatment,

Outcome 2 Disease-specific quality of life: number of women with an I-QOL score improvement $\geq 10$ points at 12

months. . . . . . . . . . . . . . . . . . . . . . . . . . . . . . . . . . . . .

Analysis 1.3. Comparison 1 Transurethral radiofrequency collagen denaturation versus no treatment/sham treatment,

Outcome 3 Clinician observations: objective measurement of incontinence: change in leak point pressure at 12 months.

Analysis 1.4. Comparison 1 Transurethral radiofrequency collagen denaturation versus no treatment/sham treatment, Outcome 4 Other adverse event: pain/dysuria: dysuria.

Analysis 1.5. Comparison 1 Transurethral radiofrequency collagen denaturation versus no treatment/sham treatment,

Outcome 5 Other adverse event: (new) detrusor overactivity: overactive bladder symptoms. . . . . . . . . . .

Analysis 1.6. Comparison 1 Transurethral radiofrequency collagen denaturation versus no treatment/sham treatment, Outcome 6 Other adverse event: de novo urinary retention: urinary retention.

Analysis 1.7. Comparison 1 Transurethral radiofrequency collagen denaturation versus no treatment/sham treatment,

Outcome 7 Other adverse event: urinary tract infection.

Analysis 1.8. Comparison 1 Transurethral radiofrequency collagen denaturation versus no treatment/sham treatment,

Outcome 8 Other adverse event: haematuria.

Analysis 1.9. Comparison 1 Transurethral radiofrequency collagen denaturation versus no treatment/sham treatment,

Outcome 9 Other adverse event: hesitancy. . . . . . . . . . . . . . . . . . . . . . . . . 35

APPENDICES . . . . . . . . . . . . . . . . . . . . . . . . . . . . . . . . . . . . . . . . . . .

CONTRIBUTIONS OF AUTHORS . . . . . . . . . . . . . . . . . . . . . . . . . . . . . . . . . . . . . . . . . . .

DECLARATIONS OF INTEREST . . . . . . . . . . . . . . . . . . . . . . . . . . . . . . . . . . . . . . . . . . . . .

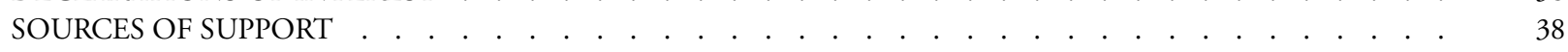

DIFFERENCES BETWEEN PROTOCOL AND REVIEW . . . . . . . . . . . . . . . . . . . . . . . . . . . . . . . 39

Transurethral radiofrequency collagen denaturation for the treatment of women with urinary incontinence (Review)

Copyright @ 2015 The Cochrane Collaboration. Published by John Wiley \& Sons, Ltd. 


\title{
[Intervention Review]
}

\section{Transurethral radiofrequency collagen denaturation for the treatment of women with urinary incontinence}

\author{
Diana Kang ${ }^{1}$, Julia $\mathrm{Han}^{2}$, Molly M Neuberger ${ }^{3}$, M. Louis Moy ${ }^{2}$, Sheila A Wallace ${ }^{4}$, Pablo Alonso-Coello ${ }^{5}$, Philipp Dahm³,6 \\ ${ }^{1}$ Department of Urology, University of California Los Angeles, Los Angeles, CA, USA. ${ }^{2}$ Department of Urology, University of Florida, \\ Gainesville, Florida, USA. ${ }^{3}$ Urology Section, Minneapolis VA Health Care System, Minneapolis, Minnesota, USA. ${ }^{4}$ Academic Urology \\ Unit, University of Aberdeen, Aberdeen, UK. ${ }^{5}$ Iberoamerican Cochrane Centre, Biomedical Research Institute Sant Pau (IIB Sant \\ Pau), Barcelona, Spain. ${ }^{6}$ Department of Urology, University of Minnesota, Minneapolis, Minnesota, USA \\ Contact address: Philipp Dahm, Urology Section, Minneapolis VA Health Care System, Minneapolis, Minnesota, USA. \\ pdahm@umn.edu.
}

Editorial group: Cochrane Incontinence Group.

Publication status and date: New, published in Issue 3, 2015.

Review content assessed as up-to-date: 19 December 2014.

Citation: Kang D, Han J, Neuberger MM, Moy ML, Wallace SA, Alonso-Coello P, Dahm P. Transurethral radiofrequency collagen denaturation for the treatment of women with urinary incontinence. Cochrane Database of Systematic Reviews 2015, Issue 3. Art. No.: CD010217. DOI: 10.1002/14651858.CD010217.pub2.

Copyright (C) 2015 The Cochrane Collaboration. Published by John Wiley \& Sons, Ltd.

\begin{abstract}
A B S T R A C T
Background

Transurethral radiofrequency collagen denaturation is a relatively novel, minimally invasive device-based intervention used to treat individuals with urinary incontinence (UI). No systematic review of the evidence supporting its use has been published to date.
\end{abstract}

\section{Objectives}

To evaluate the efficacy of transurethral radiofrequency collagen denaturation, compared with other interventions, in the treatment of women with UI.

Review authors sought to compare the following.

- Transurethral radiofrequency collagen denaturation versus no treatment/sham treatment.

- Transurethral radiofrequency collagen denaturation versus conservative physical treatment.

- Transurethral radiofrequency collagen denaturation versus mechanical devices (pessaries for UI).

- Transurethral radiofrequency collagen denaturation versus drug treatment.

- Transurethral radiofrequency collagen denaturation versus injectable treatment for UI.

- Transurethral radiofrequency collagen denaturation versus other surgery for UI.

\section{Search methods}

We conducted a systematic search of the Cochrane Incontinence Group Specialised Register (searched 19 December 2014), EMBASE and EMBASE Classic (January 1947 to 2014 Week 50), Google Scholar and three trials registries in December 2014, along with reference checking. We sought to identify unpublished studies by handsearching abstracts of major gynaecology and urology meetings, and by contacting experts in the field and the device manufacturer.

Transurethral radiofrequency collagen denaturation for the treatment of women with urinary incontinence (Review)

Copyright (c) 2015 The Cochrane Collaboration. Published by John Wiley \& Sons, Ltd. 


\section{Selection criteria}

Randomised and quasi-randomised trials of transurethral radiofrequency collagen denaturation versus no treatment/sham treatment, conservative physical treatment, mechanical devices, drug treatment, injectable treatment for UI or other surgery for UI in women were eligible.

\section{Data collection and analysis}

We screened search results and selected eligible studies for inclusion. We assessed risk of bias and analysed dichotomous variables as risk ratios (RRs) with 95\% confidence intervals (CIs) and continuous variables as mean differences (MDs) with 95\% CIs. We rated the quality of evidence using the GRADE (Grading of Recommendations Assessment, Development and Evaluation) approach.

\section{Main results}

We included in the analysis one small sham-controlled randomised trial of 173 women performed in the United States. Participants enrolled in this study had been diagnosed with stress UI and were randomly assigned to transurethral radiofrequency collagen denaturation (treatment) or a sham surgery using a non-functioning catheter (no treatment). Mean age of participants in the 12-month multicentre trial was 50 years (range 22 to 76 years).

Of three patient-important primary outcomes selected for this systematic review, the number of women reporting UI symptoms after intervention was not reported. No serious adverse events were reported for the transurethral radiofrequency collagen denaturation arm or the sham treatment arm during the 12-month trial. Owing to high risk of bias and imprecision, we downgraded the quality of evidence for this outcome to low. The effect of transurethral radiofrequency collagen denaturation on the number of women with an incontinence quality of life (I-QOL) score improvement $\geq 10$ points at 12 months was as follows: RR 1.11 , 95\% CI 0.77 to 1.62 ; participants $=142$, but the confidence interval was wide. For this outcome, the quality of evidence was also low as the result of high risk of bias and imprecision.

We found no evidence on the number of women undergoing repeat continence surgery. The risk of other adverse events (pain/dysuria $($ RR 5.73, 95\% CI 0.75 to 43.70; participants = 173); new detrusor overactivity (RR 1.36, 95\% CI 0.63 to 2.93; participants = 173); and urinary tract infection (RR $0.95,95 \%$ CI 0.24 to 3.86; participants $=173$ ) could not be established reliably as the trial was small. Evidence was insufficient for assessment of whether use of transurethral radiofrequency collagen denaturation was associated with an increased rate of urinary retention, haematuria and hesitancy compared with sham treatment in 173 participants. The GRADE quality of evidence for all other adverse events with available evidence was low as the result of high risk of bias and imprecision.

We found no evidence to inform comparisons of transurethral radiofrequency collagen denaturation with conservative physical treatment, mechanical devices, drug treatment, injectable treatment for UI or other surgery for UI.

\section{Authors' conclusions}

It is not known whether transurethral radiofrequency collagen denaturation, as compared with sham treatment, improves patientreported symptoms of UI. Evidence is insufficient to show whether the procedure improves disease-specific quality of life. Evidence is also insufficient to show whether the procedure causes serious adverse events or other adverse events in comparison with sham treatment, and no evidence was found for comparison with any other method of treatment for UI.

\section{PLAIN LANGUAGE SUMMARY}

\section{Low-temperature heat via the urethra to treat women with urinary leakage}

\section{Review question}

We studied the question of whether using low-temperature heat via the urethra is safe and helps women with involuntary urinary leakage. We looked for randomised studies comparing this treatment with no treatment or with other treatment forms.

\section{Background}

Involuntary urinary leakage is a troubling problem that many women face. Many types of treatment are available to help these women, such as changes in behaviour and different types of surgery. Low-temperature heat via the urethra is a newer form of treatment that can be used to treat women in the office rather than in the operating room. How well this treatment works and how safe it is are not well understood.

Transurethral radiofrequency collagen denaturation for the treatment of women with urinary incontinence (Review)

Copyright @ 2015 The Cochrane Collaboration. Published by John Wiley \& Sons, Ltd. 


\section{Study characteristics}

We searched for all randomised controlled trials that studied this form of treatment up to December 2014. We found only one trial of 173 women who were troubled by urinary leakage. On average, these women were 50 years of age. Through random assignment, twothirds of them were treated with low-temperature heat via the urethra; the others did not receive this treatment. Researchers followed these women for 12 months. The makers of this treatment paid for the study.

\section{Key results}

No information revealed whether more or fewer women complained of urinary leakage at 12 months, or whether there was a difference in the number of women having repeat surgery. The study did not show that quality of life was improved. Evidence was insufficient to show whether there was a difference in serious or minor side effects.

\section{Quality of the evidence}

Using the GRADE (Grading of Recommendations Assessment, Development and Evaluation) approach, we found no evidence for the question of whether low-temperature heat via the urethra changed the number of women who leaked. We found low-quality evidence related to serious side effects, minor side effects and quality of life when compared with no treatment because data were limited and the study was poorly conducted. We found no evidence on whether this treatment changed the number of women who underwent another surgery. Because we did not find studies that compared this treatment with other treatments, we do not know whether this treatment results in better or worse outcomes. 


\begin{tabular}{|c|c|c|c|c|c|c|c|}
\hline \multicolumn{8}{|c|}{ U M M A R Y C } \\
\hline$\frac{n}{3}$ & \multicolumn{7}{|c|}{ Transurethral radiofrequency collagen denaturation compared with no treatment/sham treatment for women with UI } \\
\hline 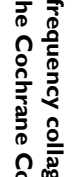 & \multicolumn{7}{|c|}{$\begin{array}{l}\text { Patient or population: women with symptomatic UI } \\
\text { Settings: academic and community practices in the United States } \\
\text { Intervention: transurethral radiofrequency collagen denaturation } \\
\text { Comparison: no treatment/sham treatment }\end{array}$} \\
\hline$\frac{10}{2}$ & \multirow[t]{3}{*}{ Outcomes } & \multicolumn{2}{|c|}{ Illustrative comparative risks* (95\% CI) } & \multirow{3}{*}{$\begin{array}{l}\text { Relative effect } \\
(95 \% \mathrm{CI})\end{array}$} & \multirow{3}{*}{$\begin{array}{l}\text { Number of participants } \\
\text { (studies) }\end{array}$} & \multirow{3}{*}{$\begin{array}{l}\text { Quality of the evidence } \\
\text { (GRADE) }\end{array}$} & \multirow[t]{3}{*}{ Comments } \\
\hline 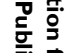 & & Assumed risk & Corresponding risk & & & & \\
\hline 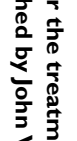 & & $\begin{array}{l}\text { No treatment/sham } \\
\text { treatment }\end{array}$ & $\begin{array}{l}\text { Transurethral radiofre- } \\
\text { quency collagen denatu- } \\
\text { ration }\end{array}$ & & & & \\
\hline 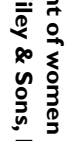 & $\begin{array}{l}\text { Participant-reported mea- } \\
\text { sures: number of women } \\
\text { reporting UI symptoms }\end{array}$ & - & - & Not estimable & 0 (0 studies) & - & No evidence available \\
\hline 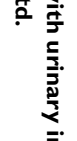 & $\begin{array}{l}\text { Serious adverse events } \\
\text { Follow-up: } 12 \text { months }\end{array}$ & 0 per 1000 & $\begin{array}{l}0 \text { per } 1000 \\
(0 \text { to } 0)\end{array}$ & Not estimable & $\begin{array}{l}173 \\
(1 \mathrm{RCT})\end{array}$ & $\begin{array}{l}\oplus \oplus \bigcirc \bigcirc \\
\mathrm{Low}^{a, b}\end{array}$ & $\begin{array}{l}\text { No serious adverse } \\
\text { events occurred in } 1 \text { in- } \\
\text { cluded study }\end{array}$ \\
\hline 兑. & $\begin{array}{l}\text { Disease-specific quality } \\
\text { of life: number of women } \\
\text { with an I-QOL score im- } \\
\text { provement } \geq 10 \text { points at } \\
12 \text { months }\end{array}$ & 434 per 1000 & $\begin{array}{l}482 \text { per } 1000 \\
\text { (334 to } 703)\end{array}$ & RR 1.11 (0.77 to 1.62$)$ & $\begin{array}{l}142 \\
(1 \mathrm{RCT})\end{array}$ & $\begin{array}{l}\oplus \oplus \bigcirc \bigcirc \\
\operatorname{Low}^{a, c}\end{array}$ & \\
\hline & $\begin{array}{l}\text { Repeat con- } \\
\text { tinence surgery: number } \\
\text { of women undergoing re- } \\
\text { peat continence surgery }\end{array}$ & - & - & Not estimable & 0 (0 studies) & - & No evidence available \\
\hline
\end{tabular}




\begin{tabular}{|c|c|c|c|c|c|}
\hline $\begin{array}{l}\text { Other adverse event: pain/ } \\
\text { dysuria: } \\
\text { dysuria } \\
\text { Follow-up: } 12 \text { months }\end{array}$ & 16 per 1000 & $\begin{array}{l}91 \text { per } 1000 \\
\text { (12 to } 694)\end{array}$ & $\begin{array}{l}\text { RR } 5.73 \\
(0.75 \text { to } 43.70)\end{array}$ & $\begin{array}{l}173 \\
(1 \mathrm{RCT})\end{array}$ & $\begin{array}{l}\oplus \oplus \bigcirc \bigcirc \\
\mathrm{Low}^{a, d}\end{array}$ \\
\hline $\begin{array}{l}\text { Other adverse event: } \\
\text { (new) detrusor overac- } \\
\text { tivity: overactive bladder } \\
\text { symptoms } \\
\text { Follow-up: } 12 \text { months }\end{array}$ & 127 per 1000 & $\begin{array}{l}173 \text { per } 1000 \\
(80 \text { to } 372)\end{array}$ & $\begin{array}{l}\text { RR } 1.36 \\
\text { (0.63 to 2.93) }\end{array}$ & $\begin{array}{l}173 \\
(1 \mathrm{RCT})\end{array}$ & $\begin{array}{l}\oplus \oplus \bigcirc \bigcirc \\
\mathrm{Low}^{a, d}\end{array}$ \\
\hline $\begin{array}{l}\text { Other adverse event: uri- } \\
\text { nary tract infection } \\
\text { Follow-up: } 12 \text { months }\end{array}$ & 48 per 1000 & $\begin{array}{l}45 \text { per } 1000 \\
\text { (11 to } 184)\end{array}$ & $\begin{array}{l}\text { RR } 0.95 \\
(0.24 \text { to } 3.86)\end{array}$ & $\begin{array}{l}173 \\
(1 \mathrm{RCT})\end{array}$ & $\begin{array}{l}\oplus \oplus \bigcirc \bigcirc \\
\mathrm{Low}^{a, d}\end{array}$ \\
\hline
\end{tabular}

*The basis for the assumed risk (e.g. median control group risk across studies) is provided in footnotes. The corresponding risk (and its $95 \% \mathrm{Cl}$ ) is based on the assumed risk in the comparison group and the relative effect of the intervention (and its $95 \% \mathrm{Cl}$ ).

CI: Confidence interval; MD: Mean difference; I-QOL: Incontinence Quality of Life; RCT: Randomised controlled trial; RR: Risk ratio; UI: Urinary incontinence.

GRADE Working Group grades of evidence.

High quality: Further research is very unlikely to change our confidence in the estimate of effect.

Moderate quality: Further research is likely to have an important impact on our confidence in the estimate of effect and may change the estimate.

Low quality: Further research is very likely to have an important impact on our confidence in the estimate of effect and is likely to change the estimate.

Very low quality: We are very uncertain about the estimate.

${ }^{a}$ Downgraded for study limitations (-1): high risk of bias.

${ }^{b}$ Downgraded for imprecision (-1): no events in small study.

cDowngraded for imprecision (-1): confidence interval includes both no effect and appreciable benefit; low numbers of events.

${ }^{d}$ Downgraded for imprecision (-1): confidence interval includes no effect and both appreciable benefit and appreciable harm; low

numbers of events. 


\section{B A C K G R O U N D}

\section{Description of the condition}

Stress urinary incontinence (SUI) is defined as the involuntary leakage of urine associated with effort, coughing or exertion (Abrams 2002). Mixed urinary incontinence (MUI) is the involuntary leakage of urine associated with urgency and also with exertion, sneezing or coughing.

\section{Pathophysiology}

Stress urinary incontinence is thought to have a complex and multi-factorial pathophysiology that relates to general weakening of the pelvic musculature and of collagen-dependent tissues involved in pelvic support (Long 2008).

Two mechanisms are well described in the literature.

- Loss of urethral support (bladder neck hypermobility).

- Rotational descent of the proximal urethra with loss of internal urethral integrity (urinary sphincter deficiency) as evidenced by funnelling within the proximal urethra (Schorge 2008).

\section{Epidemiology}

An estimated $38 \%$ of women in the United States experience some type of urinary incontinence (UI); SUI is the most common ( Abrams 2002; Anger 2006). It is estimated that more than 30\% of women 40 years of age or older have SUI. It has been shown that the annual incidence of SUI increases with age and has been reported as approximately $9 \%$ in women over 65 years of age (Imamura 2010).

\section{Risk factors}

Major risk factors for female SUI include pregnancy, vaginal delivery, parity, age, postmenopausal status and obesity (MacArthur 2006; MacLennan 2000; Thom 1997). Childbearing is the main predisposing factor specific for the development of SUI; however, the exact mechanism is unclear.

Gynaecological surgery for prolapse, hysterectomy and other gynaecological procedures double the risk of SUI (Allahdin 2008; Hampel 2004).

\section{Diagnosis}

Initial assessment of UI may include a review of the medical history, physical examination findings, a urinary diary and an incontinence questionnaire such as the International Consultation on Incontinence (ICI) Questionnaire-Short Form (ICIQ-SF for Urinary Incontinence) (Avery 2004). Urodynamics is an invasive clinical test requiring catheterisation that allows further categorisation of incontinence according to the underlying functional or anatomical cause. Its use is generally limited to individuals for whom more accurate categorisation is important (e.g. before surgical treatment) (Imamura 2010).

\section{Treatment}

Treatment for UI can be divided into non-surgical and surgical modalities. Treatment choice greatly depends on patient preference and on additional factors such as symptom severity, degree of interference with lifestyle, presence of related problems and degree of co-morbidities.

\section{Conservative and pharmacological treatment}

Non-surgical treatment options for UI usually have few adverse effects and thus are often utilised first in the treatment of UI. Several Cochrane reviews have detailed these options, which may include:

- lifestyle changes (weight loss, bladder training) (Wallace 2004);

- pelvic floor muscle training (PFMT) (Ayeleke 2013; Dumoulin 2014);

- use of devices such as pessaries or vaginal cones (Herbison 2013); and

- off-label usage of pharmacological agents (oestrogen, serotonin or noradrenaline reuptake inhibitors) (Cody 2012; Mariappan 2005).

\section{Surgical treatment}

Previous Cochrane reviews have assessed the effects of different surgical procedures performed to treat women with UI. Although the Burch colposuspension was previously considered the "gold standard" in the treatment of female UI (Lapitan 2012), midurethral slings are now considered the preferred treatment modality (Long 2008; Ogah 2009; Rehman 2011). Surgical treatments for women with UI may also include:

- urethral bulking agents (Kirchin 2012);

- open or laparoscopic colposuspension (Lapitan 2012);

- suburethral slings (Ogah 2009; Rehman 2011);

- needle suspensions (Pereyra, Stamey or Raz) (Glazener 2014);

- anterior repair (Glazener 2001); and

- radiofrequency treatment.

\section{Description of the intervention}

\section{Radiofrequency treatment}

Radiofrequency ablation (RFA) is a method of heating tissue that can cause tissue ablation and necrosis (higher temperatures) or denatured protein (lower temperatures, $65^{\circ} \mathrm{C}$ to $75^{\circ} \mathrm{C}$ ) (Takacs 
2010). Traditionally, radiofrequency treatments have been used at high temperatures with the aim of achieving tissue necrosis. Radiofrequency ablation, which is different from radiofrequency collagen denaturation, has been shown to be a safe and effective treatment option for individuals with conditions such as benign prostatic hyperplasia (Larson 2002) and hepatic metastatic disease (Fanelli 2003). Our review will focus on the use of low-level radiofrequency energy for localised collagen denaturation in the treatment of female UI.

The first system to use radiofrequency energy with micro-remodeling was the radiofrequency treatment of the endopelvic fascia, or SURx ${ }^{\mathrm{TM}}$, system (coopersurgical.com), which involved the use of a radiofrequency probe that was inserted transvaginally or laparoscopically into the endopelvic fascia, causing collagen shrinkage of periurethral tissues and reduced urethral compliance (Dmochowski 2003). The device was ultimately withdrawn by the manufacturer because of worsening of incontinence and increased incidence of complications such as vesicovaginal and urethrovaginal fistulas; for this reason, it is not included in this review (Miller 2007a).

In 2005, Novasys Medical received US Food and Drug Administration (FDA) clearance to market transurethral radiofrequency collagen denaturation under the trade name Reness ${ }^{\circledR}$ in the United States. More recently, the device used to perform this procedure has been marketed under the trade name Lyrette ${ }^{\circledR}$ by the Verathon Company (lyretterf.com). Transurethral radiofrequency collagen denaturation consists of a radiofrequency probe with a palpable balloon that is placed into the proximal urethra, where radiofrequency needles are deployed into the submucosa. Sixtysecond cycles are delivered in nine positions to a total of 36 sites using a $21 \mathrm{~F}$ transurethral delivery probe connected to a radiofrequency generator. Perceived advantages of this procedure are that it can be done in the office setting with the patient under local anaesthesia or intravenous sedation, without imaging, in less than one hour. Transurethral radiofrequency collagen denaturation is reported to be simpler than radiofrequency treatment of the endopelvic fascia and is performed using a standardised technique that is easily reproducible. It offers the additional advantage of not requiring laparoscopic or vaginal incisions, thus reducing the morbidity of the procedure.

\section{How the intervention might work}

Transurethral radiofrequency collagen denaturation administers low-temperature radiofrequency energy through a transurethral probe aimed to induce submucosal collagen denaturation while decreasing regional tissue compliance. The decrease in regional dynamic tissue compliance without tissue necrosis is intended to result in functional rather than anatomical change (Takacs 2010). Specifically, when collagen of the urethra is heated in the range of low-temperature radiofrequency energy that is administered by transurethral radiofrequency collagen denaturation (range of $65^{\circ} \mathrm{C}$ ), large domains of consecutive, intramolecular hydrogen bonds are broken, decreasing overall extensibility, and thus reducing urethral compliance (Chen 1998; Wright 2002). The maximal diameter of the urethra is reduced, stretching the surrounding urethral muscles and allowing them to function more effectively (Larson 2002). It is proposed that these mechanisms cause a decrease in funnelling and an increase in the functional length of the urethra.

\section{Why it is important to do this review}

Transurethral radiofrequency collagen denaturation was approved through the FDA $510(\mathrm{k})$ pre-market notification approval process, by which new surgical devices can be approved without additional human testing if they are substantially similar to devices already on the market, and thus are not subject to pre-market approval. Transurethral radiofrequency collagen denaturation of the urethra was approved on the basis of the previous success of RFA of metastatic liver lesions and benign prostatic hyperplasia very dissimilar disease processes. As a result of these low evidentiary standards, considerable uncertainty remains about the true therapeutic effectiveness and risks associated with this surgical device. In the United States, transurethral radiofrequency collagen denaturation is being marketed directly to consumers, and industry-funded studies advocate the procedure as effective, safe and cost-effective (Sand 2014a). Although considered investigational by many insurance providers, the procedure has a specific common procedural terminology (CPT) code (53860) to allow billing and provider reimbursement. The company website states that "the Lyrette Procedure is covered by Medicare in most states and by numerous other health insurance companies" and lists physicians throughout the United States who offer the procedure (lyretterf.com/find-a-physician). We were unable to find information about the availability of this procedure in other countries.

To date, no study has critically assessed the quality of evidence supporting the use of transurethral radiofrequency collagen denaturation, nor has any study systematically evaluated its benefits and harms. Given the availability of multiple treatment alternatives, the uncertain risks and the associated costs, an investigation of the efficacy of transurethral radiofrequency collagen denaturation appears important.

\section{O B J E C T IVES}

To evaluate the efficacy of transurethral radiofrequency collagen denaturation, compared with other interventions, in the treatment of women with urinary incontinence (UI).

Review authors sought to compare the following. 
- Transurethral radiofrequency collagen denaturation versus no treatment/sham treatment.

- Transurethral radiofrequency collagen denaturation versus conservative physical treatment.

- Transurethral radiofrequency collagen denaturation versus mechanical devices (pessaries for UI).

- Transurethral radiofrequency collagen denaturation versus drug treatment.

- Transurethral radiofrequency collagen denaturation versus injectable treatment for UI.

- Transurethral radiofrequency collagen denaturation versus other surgery for UI.

\section{METHODS}

\section{Criteria for considering studies for this review}

\section{Types of studies}

We included parallel-group randomised or quasi-randomised trials; we excluded cluster-randomised and cross-over trials.

\section{Types of participants}

Adult female patients with SUI or MUI diagnosed clinically or with urodynamics.

\section{Types of interventions}

Investigators compared transurethral radiofrequency collagen denaturation with sham treatment, no treatment, conservative physical treatment, mechanical devices (pessaries for UI), drug treatment, injectable treatment for UI or other surgery for UI.

\section{Types of outcome measures}

Measurement of outcomes assessed in this review was not a criterion for inclusion.

\section{Primary outcomes}

\section{Participant-reported measures}

Number of women reporting UI symptoms after intervention at time points defined by investigators.

\section{Serious adverse events}

Major vascular or visceral injury, bladder/urethral perforation, nerve damage, fistula formation or other major surgical complications.

\section{Disease-specific quality of life}

Disease-specific quality of life assessed through validated measures.

\section{Secondary outcomes}

\section{Repeat continence surgery}

Number of women undergoing repeat continence surgery.

\section{Participant observations}

- Overactive bladder symptoms, urgency UI.

\section{Quantification of symptoms}

- Number of pad changes.

- Pad tests (weights).

- Other quantification of symptom measures reported by individual trials.

\section{Clinician observations}

Objective measurement of incontinence (i.e. direct observation upon examination, leakage observed at urodynamics or other objective clinician observations of incontinence).

\section{Other quality of life}

- General health status measures (e.g. Short Form 36) (Ware 1993).

- Other quality of life measures reported by individual trials.

\section{Surgical outcome measures}

- Length of hospital stay.

- Time to return to normal activity level.

- Operative blood loss.

- Other surgical outcome measures reported by individual trials.

\section{Other adverse events}

- Pain, dysuria.

- (New) detrusor overactivity.

- De novo urinary retention.

- Urinary tract infection.

- Haematuria.

- Dyspareunia. 
- New prolapse.

- Other adverse events reported by individual trials.

\author{
Main outcomes for 'Summary of findings' table \\ - Number of women reporting UI symptoms. \\ - Serious adverse events. \\ - Disease-specific quality of life. \\ - Repeat continence surgery. \\ - Pain/dysuria. \\ - (New) detrusor overactivity. \\ - Urinary tract infection.
}

\section{Search methods for identification of studies}

We performed a comprehensive search on 11 January 2014 that was rerun on 19 December 2014 for both published and unpublished studies without language or other restrictions. We employed both electronic and manual searches.

\section{Electronic searches}

We searched the Cochrane Incontinence Group Specialised Register (for details, see Appendix 1), EMBASE and EMBASE Classic via Ovid SP (for search strategy, see Appendix 2) and Google Scholar (see Appendix 3) to identify relevant trials. We contacted manufacturers for information on relevant trials. We searched the FDA website (www.fda.gov/MedicalDevices/default.htm; see Appendix 4) for additional relevant documents or studies leading to approval of transurethral radiofrequency collagen denaturation. We applied no language or other restrictions. For studies identified, we contacted study authors and/or sponsors to clarify information or to request additional data points, as necessary. In addition, we searched the following clinical trials registries.

- Current Controlled Trials: www.controlled-trials.com (see Appendix 5).

- ClinicalTrials.gov: www.clinicaltrials.gov (see Appendix 6).

- World Health Organization International Clinical Trials Registry Platform (WHO ICTRP): www.who.int/ictrp/en (see Appendix 7).

\section{Searching other resources}

We scrutinised the reference lists of identified relevant studies for additional citations. We contacted specialists in the field to ask for possible unpublished data. In addition, we searched for unpublished studies by handsearching abstract proceedings from the 2003 to 2014 annual meetings of the American College of Obstetricians and Gynecologists (ACOG), American Urological Association (AUA), International Urogynecological Association (IUGA), European Association of Urology (EAU), American Association of Gynecologic Laparoscopists Advancing Minimally Invasive Gynecology Worldwide (AAGL) and International Conti- nence Society (ICS). We manually searched abstract proceedings of the American Urogynecologic Society (AUGS) for the years 2007 to 2014.

\section{Data collection and analysis}

\section{Selection of studies}

Two review authors (DK and JH) independently screened the trials for eligibility. They consulted a third review author (MLM or PD) when there was disagreement, which was also recorded. They obtained full-text articles of eligible studies and listed studies that were formally considered for the review but were excluded along with reasons for their exclusion.

\section{Data extraction and management}

Studies that met the inclusion criteria passed to the stage of data abstraction. Two review authors (DK and JH) independently conducted data abstraction using a standardised data abstraction form, which had been pilot-tested. Extracted data included study design; dates when the study was conducted; setting; participant inclusion and exclusion criteria; participant age; sample size of the study and of each intervention group; details of interventions; details of outcomes relevant to the review including how measured, time points at which they were measured and outcomes data; details of funding sources; declarations of interest among primary study authors; and study details relevant to risk of bias assessment. Analysis was based on available data from included trials relevant to comparisons and outcomes of interest. Review authors presented and considered data according to the comparisons and grouped them by outcomes. They resolved differences of opinion related to data abstraction by consensus and/or through discussion with a third review author (MLM or PD).

\section{Assessment of risk of bias in included studies}

Two review authors (DK and JH) evaluated all relevant clinical studies independently to assess methodological quality. They resolved disagreements by discussion with a third review author (MLM or PD). Each review author undertook assessment of methodological quality using the tool for assessing risk of bias of The Cochrane Collaboration (Higgins 2011a). We assessed the following domains as having low, unclear or high risk of bias.

- Random sequence generation.

- Allocation concealment.

- Blinding of participants and personnel.

- Blinding of outcome assessment.

- Incomplete outcome data.

- Selective reporting.

- Other sources of bias. 
We assessed blinding of participants and personnel, blinding of outcome assessment and incomplete outcome data on an outcomespecific basis, as the risk of bias of each of these domains is likely to vary by outcome.

We grouped outcomes as subjective and objective for outcomespecific risk of bias assessments in blinding domains. For the three primary outcomes, we considered the number of women reporting UI symptoms and disease-specific quality of life as subjective outcomes, whereas we categorised occurrence of a serious adverse event as an objective outcome.

We rated as subjective all secondary outcomes except for quantification of symptoms (e.g. number of pad changes), length of hospital stay, operative blood loss, occurrence of haematuria, urinary tract infection, urinary retention, repeat continence surgery, new prolapse and objective measurement of incontinence (e.g. change in leak point pressure).

For the incomplete outcome data domain, we grouped outcomes that had similar circumstances related to completeness of data.

\section{Measures of treatment effect}

We analysed the extracted data using Review Manager software (RevMan 2014). For dichotomous variables, we extracted numbers of events and totals to calculate risk ratios (RRs) and 95\% confidence intervals (CIs). If numbers of events were unavailable, we used reported percentages of participants experiencing the outcome and total numbers of participants assessed to calculate the numbers of events. For continuous outcomes, we extracted means, standard deviations and totals to calculate mean differences (MDs) and $95 \%$ CIs.

\section{Unit of analysis issues}

We included only randomised and quasi-randomised controlled trials; we excluded cluster-randomised and cross-over trials. Although they were eligible for inclusion, we identified no studies with multiple intervention groups.

\section{Dealing with missing data}

We contacted the original investigators to request missing data so we could analyse all data by performing an intention-to-treat (ITT) analysis. However, we obtained no additional data. We therefore based analyses on available data only. We identified nonITT analyses in the Results section as available case analyses accordingly.

\section{Assessment of heterogeneity}

We planned to assess heterogeneity by visually inspecting the forest plots and by using the $\mathrm{I}^{2}$ statistic (Higgins 2002; Higgins 2003). We defined the thresholds for interpretation of the $\mathrm{I}^{2}$ statistic according to the Cochrane Handbook for Systematic Reviews of Interventions (Deeks 2011): < 30\% heterogeneity may not be impor- tant, $30 \%$ to $50 \%$ may represent moderate heterogeneity and > $50 \%$ may represent substantial/considerable heterogeneity. Heterogeneity was not a factor because of the number of studies included in the review.

\section{Assessment of reporting biases}

To minimise the impact of possible publication bias, we conducted electronic and manual searches of multiple databases, including registries, without language restriction, to identify published and unpublished studies. Fewer than 10 studies were available; therefore we did not conduct a test for funnel plot asymmetry to assess potential publication bias. We attempted to obtain study protocols to assess for reporting bias.

\section{Data synthesis}

We planned to pool data from eligible studies to estimate a pooled effect size and to generate the corresponding forest plots. We planned to perform meta-analysis using a random-effects model with the Mantel-Haenszel method for dichotomous data and with the inverse variance method for continuous data. Given that only a single eligible trial was identified, we conducted no meta-analysis.

\section{Subgroup analysis and investigation of heterogeneity}

If relevant data were available (subgroups already stratified in the study), we planned to explore the following potential sources of heterogeneity using subgroup analyses based on four a priori defined hypotheses (with prespecified direction) and to perform additional testing for interaction.

- Participant age (50 years of age vs older; better outcomes in younger participants).

- Menopausal status (before vs after; better outcomes in premenopausal women).

- Presence or absence of prolapse (yes vs no; better outcomes when prolapse was absent).

- History of prior surgical procedure for treatment of individuals with UI (yes vs no; better outcomes with no prior surgical procedure).

Given that limited data were identified, none of the prespecified subgroup analyses were possible. We report a post hoc subgroup analysis performed by degree of baseline UI (mild vs moderate to severe), as provided by the trial investigators.

\section{Sensitivity analysis}

We planned to investigate the robustness of results by performing a sensitivity analysis based on methodological quality as defined in the Cochrane Handbook for Systematic Reviews of Interventions (Higgins 2011b) and to report the results in a summary table. Given the paucity of data, we performed no sensitivity analysis. 


\section{'Summary of findings' table}

We rated the overall quality of evidence using the GRADE framework, with consideration of study limitations (risk of bias), inconsistency, indirectness, imprecision and publication bias, and we presented this information in a 'Summary of findings' table (Guyatt 2008; Guyatt 2011; Schünemann 2011).

R E S U L T S

\section{Description of studies}

See Characteristics of included studies and Characteristics of excluded studies.

\section{Results of the search}

For this review, we identified 253 records through the search and retrieved 28 full-text articles; of these, we excluded 25 reports of 21 studies and provided reasons in the Characteristics of excluded studies table. None of the abstracts or presentations provided additional relevant trial data that met our study inclusion criteria. One study met eligibility criteria and was included (Appell 2006). See Figure 1 for a flow diagram of the search. 
Figure I. Study flow diagram.

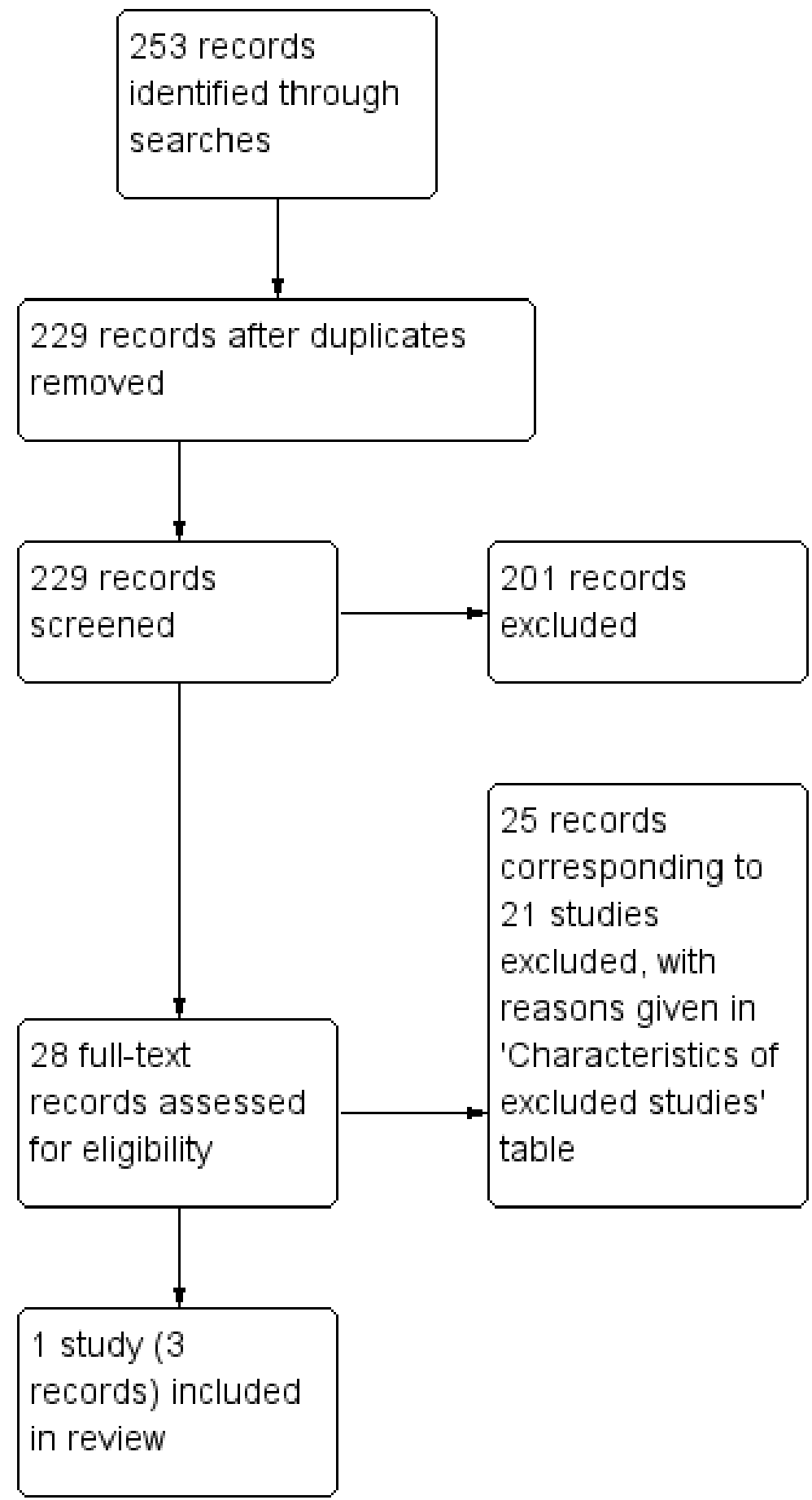




\section{Included studies}

We included in the analysis one sham-controlled randomised trial in women with SUI conducted in the United States of America (Appell 2006). In this study, 110 women underwent transurethral radiofrequency collagen denaturation in the treatment arm and 63 underwent sham treatment in the control arm. Mean participant age was 50 years (range 22 to 76 years), and mean duration of SUI was eight years (range one to 49 years). All participants were treated with the same type of radiofrequency probe (Novasys Medical, Inc., Newark, California) and one of two similar radiofrequency generators (Novasys Medical, Inc.; Curon Medical, Inc., Fremont, California; Appell 2006).

Incontinence quality of life (I-QOL) score improvement of 10 or more points and change in leak point pressure (LPP) were assessed at six months and 12 months of follow-up to look for improvement among the two groups. Adverse events and postoperative level of discomfort were also assessed. The study was funded by a grant from Novasys Medical, Inc., the manufacturer of the transurethral radiofrequency collagen denaturation device at that time. For more information, see Characteristics of included studies.

\section{Excluded studies}

We excluded 21 studies after performing full-text assessment for eligibility.

We excluded four studies because they were observational studies of single-armed cohorts (Elser 2009; Lenihan 2005; Sotomayor 2003; Wells 2007). Of these four observational studies, two were original cohort studies that assessed the primary outcome of this review (Elser 2009; Sotomayor 2003) and two did not assess the primary outcome of the systematic review (Lenihan 2005; Wells 2007). One study performed a cost analysis of transurethral radiofrequency collagen denaturation (Sand 2014b). Another study was an ongoing multi-centre prospective single-armed trial of transurethral collagen denaturation funded by the Verathon Corporation to study the Lyrette ${ }^{\circledR}$ device (Lukban 2013a). Results at 12 months of follow-up have been presented at society meetings as abstracts without a full-text study report (Lukban 2013a). As a single-armed study, this trial did not meet inclusion criteria for this review. For more information, see Characteristics of excluded studies.

We identified no studies comparing the efficacy of transurethral radiofrequency collagen denaturation versus conservative physical treatment, use of mechanical devices (such as a pessary), drug treatment, injectable treatment or other surgery for UI.

\section{Risk of bias in included studies}

We assessed risk of bias on an outcome-specific basis.

\section{Allocation}

\section{Random sequence generation}

The trial used a computer-generated allocation sequence with a 2 : 1 ratio. We judged risk of bias to be low for all outcomes.

\section{Allocation concealment}

Allocation concealment was not reported. We rated risk of bias as unclear for all outcomes.

\section{Blinding}

We grouped outcomes as subjective and objective for outcomespecific risk of bias assessments in blinding domains.

\section{Blinding of participants and personnel}

Although participants were reported to be blinded using a sham design, the study did not report blinding of study personnel. As blinding of personnel was not reported, we judged the risk of performance bias to be unclear for both subjective and objective outcomes.

\section{Blinding of outcome assessment}

Blinding of outcome assessors was not reported in the included study. We rated the risk of bias as low for objective outcomes and as unclear for subjective outcomes.

\section{Incomplete outcome data}

We grouped categories of outcomes that had similar circumstances related to completeness of data for outcome-specific assessment of the incomplete outcome data risk of bias domain.

At 12 months, $82 \%$ of the enrolled population were evaluated for $\geq 10$-point I-QOL score improvement. Twenty-one women (12\%) were lost to follow-up, and eight women had changes in their medical history that excluded them from the study (hysterectomy or urinary tract infection (UTI) at 12 months). As UTI was an adverse event evaluated in the study, the completeness of data for this primary subjective outcome is questionable. Two women had baseline I-QOL scores $>90$ and therefore could not have a $\geq 10$-point improvement. The percentage of participants in each group who were lost to follow-up or were otherwise considered unevaluable and excluded from analysis was similar. We judged risk of bias for this disease-specific quality of life outcome to be high. 
The included study assessed changes in LPP among participants; however only $78.6 \%$ were evaluated. A similar percentage of participants in each group was lost to follow-up or was otherwise considered unevaluable and was excluded from analysis. Risk of bias was rated as high for this objective measurement of incontinence. For other outcomes reported in the included study, completeness of outcome data was not reported. We judged risk of bias as unclear for these outcomes.

\section{Selective reporting}

In the Methods section, trial investigators reported that the study's main outcomes ( $\geq 10$-point I-QOL score improvement and change in LPP) were assessed at six months and at 12 months; however, no six-month data were presented. We therefore rated the study to be at high risk for selective reporting.

\section{Other potential sources of bias}

Investigators provided a subgroup analysis that stratified participants as having mild versus moderate/severe UI at baseline. No trial protocol was available, and investigators provided no rationale for the grouping. We rated this analysis as having high risk of bias and the positive findings as at risk for being spurious.

\section{Effects of interventions}

See: Summary of findings for the main comparison Transurethral radiofrequency collagen denaturation compared with no treatment/sham treatment for women with UI

\section{Transurethral radiofrequency collagen denaturation versus no treatment/sham treatment}

Primary outcomes
Participant-reported measures

Number of women reporting UI symptoms after intervention at time points defined by investigators

We found no data reported for this outcome measure (Summary of findings for the main comparison).

Serious adverse events

Major vascular or visceral injury, bladder/urethral perforation, nerve damage, fistula formation or other major surgical complications

No serious adverse events were recorded in the treatment group or the control group during the 12-month trial (one study; 173 participants; Analysis 1.1), although the trial authors did not define 'serious adverse event'. Risk of bias was high and imprecision was a matter of concern for this outcome; the GRADE quality of the evidence was downgraded by two levels to low (Summary of findings for the main comparison).

Disease-specific quality of life

\section{Disease-specific quality of life assessed through validated measures}

Transurethral radiofrequency collagen denaturation was not associated with an increase in the number of women with an I-QOL score improvement greater than or equal to 10 points at 12 months when compared with sham treatment in an analysis of available data (RR 1.11, 95\% CI 0.77 to 1.62 ; participants = 142; studies $=1$; Analysis 1.2; Figure 2). We downgraded the quality of the evidence by two levels to low because of high risk of bias and imprecision (Summary of findings for the main comparison).

Figure 2. Forest plot of comparison: I Transurethral radiofrequency collagen denaturation versus no treatment/sham treatment, outcome: I.2 Disease-specific quality of life: number of women with an I-QOL score improvement greater than or equal to 10 points at 12 months.

\begin{tabular}{|c|c|c|c|c|c|c|c|c|}
\hline Study or Subgroup & \multicolumn{2}{|c|}{ RF treatment } & \multicolumn{2}{|c|}{ Control } & $\begin{array}{c}\text { Risk Ratio } \\
\text { M-H, Random, } 95 \% \mathrm{Cl}\end{array}$ & \multicolumn{3}{|c|}{$\begin{array}{c}\text { Risk Ratio } \\
\text { M-H, Random, } 95 \% \text { Cl }\end{array}$} \\
\hline Appell 2006 & 43 & 89 & 23 & 53 & $1.11[0.77,1.62]$ & & 1 & \\
\hline
\end{tabular}

Transurethral radiofrequency collagen denaturation for the treatment of women with urinary incontinence (Review) 
We found no available evidence for this outcome.

Repeat continence surgery

\section{Number of women undergoing repeat continence surgery}

We found no available evidence for this outcome (Summary of findings for the main comparison).

Participant observations

\section{Overactive bladder symptoms, urgency UI}

We found no available evidence for this outcome.

Quantification of symptoms

\section{Number of pad changes}

We found no available evidence for this outcome.

Pad tests (weights)
Other quantification of symptom measures reported by individual trials

We found no available evidence for this outcome.

Clinician observations

Objective measurement of incontinence (such as direct observation upon examination, leakage observed at urodynamics or other objective clinician observations of incontinence)

Mean change in LPP at 12 months was $-13.2 \pm 39.2 \mathrm{~cm} \mathrm{H}_{2} \mathrm{O}$ in women in the treatment arm and $2.0 \pm 33.8 \mathrm{~cm} \mathrm{H}_{2} \mathrm{O}$ in women in the sham treatment arm, with a lower mean representing a better outcome. In an analysis of available data at 12 months, mean LPP change was significantly improved in the transurethral radiofrequency collagen denaturation group (MD -15.20, 95\% CI -27.75 to -2.65 ; participants $=136$; studies $=1$; Analysis 1.3; Figure 3), with a MD less than zero favouring the treatment group. However, the effects were uncertain because evidence was of very low quality as the result of high risk of bias, indirectness and imprecision.

Figure 3. Forest plot of comparison: I Transurethral radiofrequency collagen denaturation versus no treatment/sham treatment, outcome: I.3 Clinician observations: objective measurement of incontinence: change in leak point pressure at 12 months.

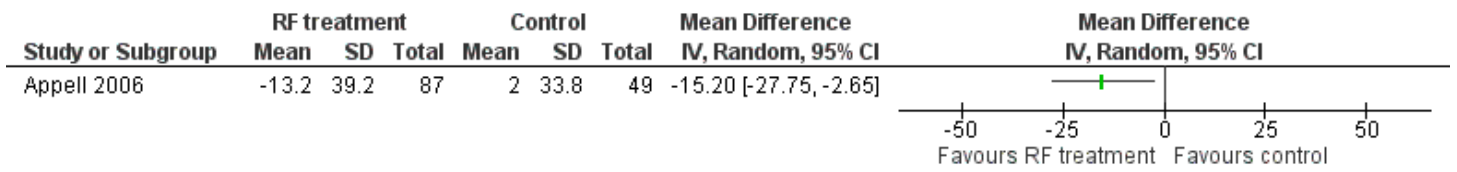

Other quality of life

Surgical outcome measures

General health status measures (e.g. Short Form 36)

We found no available evidence for this outcome.

\section{Length of hospital stay}

We found no available evidence for this outcome.
Other quality of life measures reported by individual trials

We found no available evidence for this outcome.
Time to return to normal activity level

We found no available evidence for this outcome.

Transurethral radiofrequency collagen denaturation for the treatment of women with urinary incontinence (Review) 
Operative blood loss

We found no available evidence for this outcome. study limitations and imprecision.

Other adverse events

\section{Other surgical outcome measures reported by individual trials}

The one included study (participants $=173$ ) reported that the level of postoperative discomfort as assessed on a visual analogue scale from 0 (no pain) to 10 (terrible pain) was not significantly different in the treatment arm versus the control arm. However, control group data were not available to the review authors to allow for calculation of the effect estimate and the confidence interval. The quality of the evidence was very low as the result of very serious

\section{Pain, dysuria}

Dysuria occurred in $9.1 \%$ of actively treated participants and in $1.6 \%$ of sham-treated participants (RR 5.73 , 95\% CI 0.75 to 43.70; participants $=173$; studies $=1$; Analysis 1.4; Figure 4) . The quality of the evidence was downgraded by two levels to low because of high risk of bias and imprecision (Summary of findings for the main comparison).

Figure 4. Forest plot of comparison: I Transurethral radiofrequency collagen denaturation versus no treatment/sham treatment, outcome: I.4 Other adverse event: pain/dysuria: dysuria.

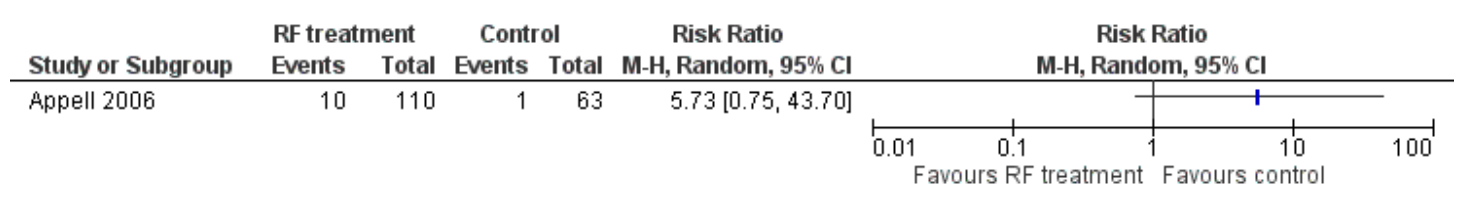

(New) detrusor overactivity

Dry overactive bladder was more common in the transurethral radiofrequency collagen denaturation arm $(7.3 \%$ vs $3.2 \%)$, but this finding was not statistically significant. Very little difference in the prevalence of wet overactive bladder was noted between groups ( $10 \%$ vs $9.5 \%)$. When we combined the dry overactive bladder data and the wet overactive bladder data, we found no evidence of a difference in effect on overactive bladder symptoms between groups (RR 1.36, 95\% CI 0.63 to 2.93; participants = 173; studies $=1$; Analysis 1.5 ). We downgraded the quality of the evidence to low as the result of high risk of bias and imprecision (Summary of findings for the main comparison).

\section{De novo urinary retention}

Urinary retention occurred rarely: One participant in the treatment arm developed urinary retention, and it was unclear as to whether this was of new onset (RR $1.73,95 \%$ CI 0.07 to 41.84 ; participants $=173$; studies $=1$; Analysis 1.6; Figure 5). We judged the quality of the evidence as low because of high risk of bias and imprecision.

Figure 5. Forest plot of comparison: I Transurethral radiofrequency collagen denaturation versus no treatment/sham treatment, outcome: I.6 Other adverse event: de novo urinary retention: urinary retention.

\begin{tabular}{|c|c|c|c|c|c|c|c|c|c|}
\hline \multirow[b]{2}{*}{ Study or Subgroup } & \multicolumn{2}{|c|}{ RF treatment } & \multicolumn{2}{|c|}{ Control } & \multirow{2}{*}{$\begin{array}{c}\text { Risk Ratio } \\
\text { M-H, Random, } 95 \% \mathrm{Cl}\end{array}$} & \multirow{2}{*}{\multicolumn{4}{|c|}{$\begin{array}{c}\text { Risk Ratio } \\
\text { M-H, Random, } \mathbf{9 5} \% \mathrm{Cl}\end{array}$}} \\
\hline & Events & Total & Events & Total & & & & & \\
\hline Appell 2006 & 1 & 110 & 0 & 63 & $1.73[0.07,41.84]$ & & & 1 & \\
\hline & & & & & & 0.01 & $\begin{array}{l}0.1 \\
\text { S RF }\end{array}$ & $\begin{array}{cc}10 \\
\text { Favours contro }\end{array}$ & 100 \\
\hline
\end{tabular}

Transurethral radiofrequency collagen denaturation for the treatment of women with urinary incontinence (Review) 


\section{Urinary tract infection}

Urinary tract infection was observed to occur equally when treatment was compared with sham treatment $(4.5 \%$ vs $4.8 \%$, respectively), and the results were not statistically significant (RR 0.95, 95\% CI 0.24 to 3.86; participants $=173$; studies $=1$; Analysis 1.7). The quality of the evidence was low as the result of downgrades for high risk of bias and imprecision (Summary of findings for the main comparison).

\section{Haematuria}

One participant in the treatment arm developed haematuria $(0.9 \%)$, but this finding was not statistically significant (RR 1.73 , 95\% CI 0.07 to 41.84; participants = 173; studies = 1; Analysis 1.8; Figure 6). Further research is very likely to change the effect estimate because low-quality evidence was downgraded for high risk of bias and imprecision.

Figure 6. Forest plot of comparison: I Transurethral radiofrequency collagen denaturation versus no treatment/sham treatment, outcome: I.8 Other adverse event: haematuria.

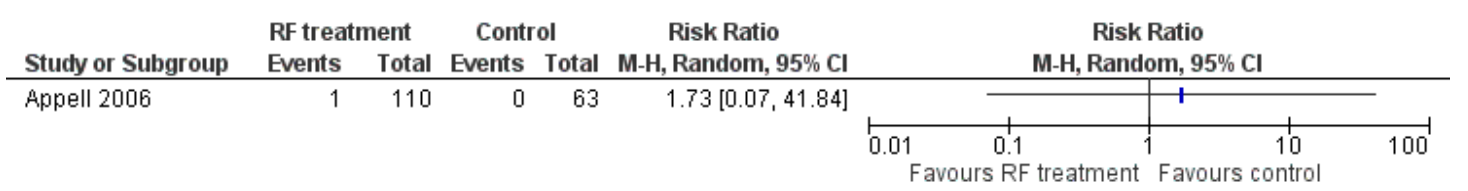

\section{Dyspareunia}

We found no available evidence for this outcome.

\section{New prolapse}

We found no available evidence for this outcome.

\section{Other adverse events reported by individual trials}

Hesitancy was reported by one participant in the sham treatment arm $(1.6 \%)$ and by no participants in the treatment arm $(0 \%)$, but this finding was not statistically significant (RR 0.19, 95\% CI 0.01 to 4.65; participants $=173$; studies $=1$; Analysis 1.9). High risk of bias and imprecision resulted in downgrading of the quality of the evidence to low.

\section{Subgroup analyses}

Given the absence of data, we were unable to perform subgroup analyses based on the pre-identified prognostic variables, which included participant age, menopausal status, presence or absence of prolapse and history of prior surgical procedure for UI.

In an available case subgroup analysis not prespecified in this review, investigators grouped participants on the basis of their level of baseline incontinence into 'mild' and 'moderate to severe' groups. In women with mild incontinence, the RR when treatment was compared with sham treatment for the outcome of number of women with an I-QOL score improvement greater than or equal to 10 points at 12 months was 0.63 (95\% CI 0.29 to 1.37 ; P value 0.24 ; participants $=69$; studies $=1$; analysis not shown). In women with moderate to severe incontinence, the RR was 1.49 (95\% CI 1.00 to 2.22; $\mathrm{P}$ value 0.05 ; participants $=73$; studies $=$ 1 ; analysis not shown). In these subgroups, according to baseline incontinence, the GRADE quality of the evidence was very low because of downgrading by two levels for high risk of bias and by one level for imprecision. No data were available to permit the same subgroup analyses for other outcomes.

\section{Transurethral radiofrequency collagen denaturation versus conservative physical treatment}

We found no available evidence for this comparison.

\section{Transurethral radiofrequency collagen denaturation versus mechanical devices (pessaries for UI)}

We found no available evidence for this comparison.

\section{Transurethral radiofrequency collagen denaturation versus drug treatment}

We found no available evidence for this comparison. 
Transurethral radiofrequency collagen denaturation versus injectable treatment for $U I$

We found no available evidence for this comparison.

\section{Transurethral radiofrequency collagen denaturation versus other surgery for $U$ I}

We found no available evidence for this comparison.

\section{DISCUSSION}

\section{Summary of main results}

We systematically reviewed the quality of existing evidence on transurethral radiofrequency collagen denaturation for the treatment of female UI. Only one small sham-controlled randomised trial, which enrolled women with SUI, met inclusion criteria for this systematic review (Appell 2006).

The trial did not report any evidence with regards to the impact of transurethral radiofrequency collagen denaturation on one of the primary outcomes of the review - the number of women reporting UI symptoms (Summary of findings for the main comparison). The trialists reported that no serious adverse events occurred in either the treatment arm or the control arm of the trial (Summary of findings for the main comparison), but the trial was small and further research is likely to change the estimate. In the included study, investigators found no statistically significant differences in disease-specific quality of life, as measured by the number of women with an I-QOL score improvement greater than or equal to 10 points, between the women who underwent transurethral radiofrequency collagen denaturation and those who underwent sham treatment at 12 months (Summary of findings for the main comparison). However, the trial was small and the confidence intervals wide. The study reported no evidence with regards to the number of women undergoing repeat continence surgery (Summary of findings for the main comparison). The trial was too small to reliably detect differences between groups in the occurrence of other adverse events, such as pain/dysuria, (new) detrusor overactivity, urinary tract infection, urinary retention, haematuria or hesitancy (Summary of findings for the main comparison).

We found no trials of comparisons between transurethral radiofrequency collagen denaturation and conservative physical treatment, mechanical devices, drug treatment, injectable treatment for UI or other surgery for UI.

\section{Overall completeness and applicability of evidence}

This review highlighted substantial gaps in the evidence, as we were unable to find any studies comparing transurethral radiofrequency collagen denaturation versus five of the predefined types of comparators: conservative physical treatment, mechanical devices, drug treatment, injectable treatment and other surgery for UI. One randomised controlled trial comparing transurethral radiofrequency collagen denaturation versus sham treatment was systematically reviewed. The single included study did not assess our previously stated primary outcome of the number of women reporting UI symptoms after treatment. The one comparison study analysed did not address a number of our secondary outcomes, including the need for further incontinence procedures, dyspareunia and new prolapse development.

The trial involved both academic and community urologists and urogynaecologists, thereby enhancing the generalisability of its findings. The most noteworthy exclusion criterion limiting applicability was the exclusion of women with pre-existing overactive bladder symptoms and/or documentation of bladder overactivity. Also, SUI was the only form of UI examined in the trial. Women who had undergone any prior procedure for UI were excluded.

\section{Quality of the evidence}

With regards to the primary outcomes of this review, no randomised trial evidence was found to inform our understanding of the impact of transurethral radiofrequency collagen denaturation on individual, patient-reported symptoms of UI. The quality of evidence for the absence of treatment-associated serious adverse events was rated as low, mainly because of concerns over risk of bias and imprecision. The quality of evidence for the outcome of disease-specific quality of life was rated as low because of risk of bias and imprecision. Of particular concern with respect to risk of bias was the failure of study authors to account for all participants in the outcome analysis.

We found no evidence for the secondary, main outcome of number of women undergoing repeat continence surgery. The quality of evidence for the other secondary, patient-reported main outcomes was rated as low according to GRADE. We downgraded for risk of bias as well as imprecision.

Consideration of inconsistency, indirectness and publication bias did not result in any further downgrading of the quality of evidence for the main outcomes.

Overall, the quality of the body of evidence contributing to the comparison of transurethral radiofrequency collagen denaturation versus sham treatment in this review was low, and evidence was lacking for the other five predefined comparisons.

\section{Potential biases in the review process}

Our risk of bias assessment was based on the full-text publication of the study by Appell et al (Appell 2006) and the methodolog- 
ical detail it provided; however, the actual methodological quality of the published study may have been better than reported (Devereaux 2004). Unfortunately, attempts to obtain further information from the principal investigator were limited by his recent passing. The recent change in the company that markets the device in the United States to perform this surgical procedure may have been an additional barrier towards acquiring additional information. We contacted the manufacturer and the secondary authors of the study but received no additional information that would change our assessment of the methodological quality of the study.

\section{Agreements and disagreements with other studies or reviews}

A technology assessment and review of the literature on transurethral radiofrequency collagen denaturation was published by the California Technology Assessment Forum in 2008 (Karliner 2008). It does not include several studies that were published after that time period, but it does include an analysis on the modality of laparoscopic and transvaginal radiofrequency denaturation, which has since been withdrawn from the market and was not within the scope of this Cochrane review.

A narrative review on transurethral radiofrequency collagen denaturation was published in 2012 (Lukban 2012b). However, it did not apply established systematic review methodology, which includes a comprehensive search for both published and unpublished studies and a critical appraisal of the quality of evidence, as was applied in this Cochrane review.

\section{Implications for practice}

This systematic review questions the therapeutic efficacy of transurethral radiofrequency collagen denaturation to treat female UI. The included trial was too small to detect any rare serious adverse events, and we were unable to establish the impact of this approach on individual patient-reported UI symptoms. Evidence was insufficient to detect a difference in disease-specific quality of life when compared with sham treatment, and we are uncertain of the findings because the quality of the evidence was low.

Effects of transurethral radiofrequency collagen denaturation compared with conservative physical treatment, mechanical devices, drug treatment, injectable treatment for UI or other surgery for $\mathrm{UI}$ are unclear, as we found no available evidence to inform these comparisons.

\section{Implications for research}

The findings of this review were based on a single, sham-controlled randomised trial at high risk of bias that did not address patientreported symptoms of UI. Before this intervention is made available to women, more rigorous and adequately powered trials are required to assess the relative benefits and adverse event profile of transurethral radiofrequency collagen denaturation as compared with other minimally invasive, active treatment options such as use of a urethral bulking agent injection or suburethral slings. These trials should be carefully designed and executed with a focus on patient-important outcomes, transparently reported and adequately powered to provide definitive results.

\section{ACKNOWLEDGEMENTS}

The review authors thank the Cochrane Incontinence Group for its support.

\section{AUTHORS' CONCLUSIONS}

\section{RE F E R E N C E S}

\section{References to studies included in this review}

Appell 2006 \{published data only (unpublished sought but not used)\}

* Appell RA, Juma S, Wells WG, Lenihan JP, Klimberg

IW, Kanellos A, et al. Transurethral radiofrequency energy collagen micro-remodeling for the treatment of female stress urinary incontinence. Neurourology and Urodynamics 2006; 25(4):331-6.

Appell RA, Singh G, Klimberg IW, Graham C, Juma S, Wells WG, et al. Nonsurgical, radiofrequency collagen denaturation for stress urinary incontinence: retrospective 3-year evaluation. Expert Review of Medical Devices 2007;4 (4):455-61.

Lenihan JP Jr. Comparison of the quality of life after nonsurgical radiofrequency energy tissue micro-remodeling in premenopausal and postmenopausal women with moderate-to-severe stress urinary incontinence. American Journal of Obstetrics and Gynecology 2005;192(6):1995-8.

\section{References to studies excluded from this review}

Appell 2007 \{published data only\}

Appell RA, Davila G. Treatment options for patients with suboptimal response to surgery for stress urinary incontinence. Current Medical Research and Opinion 2007; 23(2):285-92.

Appell 2008 \{published data only\} Appell RA. Transurethral collagen denaturation for women with stress urinary incontinence. Current Urology Reports 2008;9(5):373-9. 
Crivellaro 2009 \{published data only\}

Crivellaro S, Smith JJ. Minimally invasive therapies for female stress urinary incontinence: the current status of bioinjectables/new devices (adjustable continence therapy, urethral submucosal collagen denaturation by radiofrequency). The Scientific World Journal 2009;9: 466-78.

Davila 2011 \{published data only\}

Davila GW. Nonsurgical outpatient therapies for the management of female stress urinary incontinence: longterm effectiveness and durability. Advances in Urology 2011; 2011:176498.

Dillon 2009 \{published data only\}

Dillon B, Dmochowski R. Radiofrequency for the treatment of stress urinary incontinence in women. Current Urology Reports 2009;10(5):369-74

Dmochowski 2002 \{published data only\} Dmochowski RR. Radiofrequency bladder neck suspension for the treatment of genuine stress urinary incontinence. Current Urology Reports 2002;3(5):378-81.

Edelstein 2006 \{published data only\} Edelstein PS. A preclinical study of nonsurgical radiofrequency collagen remodeling for the treatment of stress urinary incontinence. Expert Review of Medical Devices 2006;3(6):743-8.

Elser 2007 \{published data only\}

Elser DM. Stress urinary incontinence in women: what options lie between traditional therapies and surgery?. Women's Health (London, England) 2007;3(6):725-33.

Elser 2009 \{published data only\}

Elser DM, Mitchell GK, Miklos JR, Nickell KG, Cline $\mathrm{K}$, Winkler $\mathrm{H}$, et al. Nonsurgical transurethral collagen denaturation for stress urinary incontinence in women: 12month results from a prospective long-term study. Journal of Minimally Invasive Gynecology 2009;16(1):56-62. Elser DM, Mitchell GK, Miklos JR, Nickell KG, Cline $\mathrm{K}$, Winkler $\mathrm{H}$, et al. Nonsurgical transurethral collagen denaturation for stress urinary incontinence in women: 18-month results from a prospective long-term study. Neurourology and Urodynamics 2010;29(8):1424-8. Elser DM, Mitchell GK, Miklos JR, Nickell KG, Cline K, Winkler $\mathrm{H}$, et al. Nonsurgical transurethral radiofrequency collagen denaturation: results at three years after treatment. Advances in Urology 2011;2011:872057.

Gilleran 2005 \{published data only\}

Gilleran JP, Zimmern P. An evidence-based approach to the evaluation and management of stress incontinence in women. Current Opinion in Urology 2005;15(4):236-43.

Juma 2007 \{published data only\}

Juma S, Appell RA. Nonsurgical transurethral radiofrequency treatment of stress urinary incontinence in women. Women's Health (London, England) 2007;3(3): 291-9.

Lenihan 2005 \{published data only\}

Lenihan JP, Palacios P, Sotomayor M. Oral and local anesthesia in the nonsurgical radiofrequency-energy treatment of stress urinary incontinence. Journal of

Minimally Invasive Gynecology 2005;12(5):415-9.

Lukban 2012a \{published data only\}

Lukban JC. Transurethral radiofrequency collagen denaturation for treatment of female stress urinary incontinence: a review of the literature and clinical recommendations. Obstetrics and Gynecology International 2012;2012:384234.

Lukban 2013a \{published data only\}

Lukban J, Takacs P, Crisell M, Van Drie D, Elser D, Bressman P, et al. Transurethral radiofrequency collagen denaturation in the treatment of mild to moderate female stress urinary incontinence: twelve-month interim analysis. Journal of Urology 2014;191(4 Suppl):e402-3.

Lukban JC, Crisell MS, Van Drie D, Elser DM, Bressman PL, Adkins RT, et al. Transurethral radiofrequency collagen denaturation in the treatment of mild to moderate female stress urinary incontinence: six-month interim analysis. Journal of Minimally Invasive Gynecology 2013;20(6 Suppl): S71-2.

Lukban 2013b \{published data only\}

Lukban JC, Adkins RT. Office-based anesthesia for the Lyrette procedure for female stress urinary incontinence. http://lyrettemd.com/wp-content/uploads/2013/03/ Anesthesia 'White' Paper.pdf (accessed 9 January 2014).

Miller 2007b \{published data only\} Miller D. Office management of stress incontinence: current and future role. Clinical Obstetrics and Gynecology 2007;50(2):376-82.

Sand 2014b \{published data only\}

Sand PK, Owens GM, Black EJ, Anderson LH, Martinson MS. Cost effectiveness of radiofrequency microremodeling for stress urinary incontinence. International Urogynecology Journal 2014;25(4):517-23.

Sotomayor 2003 \{published data only\} Sotomayor M, Bernal GF. Transurethral delivery of radiofrequency energy for tissue micro-remodeling in the treatment of stress urinary incontinence. International Urogynecology Journal 2003;14(6):373-9.

Sotomayor M, Bernal GF. Twelve-month results of nonsurgical radiofrequency energy micro-remodeling for stress incontinence. International Urogynecology Journal 2005;16(3):192-6.

Takacs 2013 \{published data only\}

Takacs P, Nguyen A. Mechanism of action of the Lyrette $^{\mathrm{TM}}$ treatment for stress urinary incontinence. http://lyrettemd.com/wp-content/uploads/2013/03/ Mechanism 'White' Paper.pdf (accessed 9 January 2014).

Vianello 2007 \{published data only\}

Vianello A, Costantini E, Del Zingaro M, Porena M. Miniinvasive techniques for the treatment of female stress urinary incontinence. Minerva Ginecologica 2007;59(6):557-69.

Wells 2007 \{published data only\}

Wells WG, Lenihan JP Jr. Use of in-office anesthesia during non-surgical radiofrequency collagen denaturation for stress 
urinary incontinence. Current Medical Research and Opinion 2007;23(6):1279-84.

\section{Additional references}

\section{Abrams 2002}

Abrams P, Cardozo L, Fall M, Griffiths D, Rosier P, Ulmsten $\mathrm{U}$, et al. The standardisation of terminology of lower urinary tract function: report from the Standardisation Sub-committee of the International Continence Society. American Journal of Obstetrics and Gynecology 2002;187(1): 116-26.

\section{Allahdin 2008}

Allahdin S, Harrild K, Warraich QA, Bain C. Comparison of the long-term effects of simple total abdominal hysterectomy with transcervical endometrial resection on urinary incontinence. BJOG 2008;115(2):199-204.

\section{Anger 2006}

Anger JT, Saigal CS, Litwin MS, The Urologic Diseases of America Project. The prevalence of urinary incontinence among community dwelling adult women: results from the National Health and Nutrition Examination Survey. Journal of Urology 2006;175(2):601-4.

Avery 2004

Avery K, Donovan J, Peters TJ, Shaw C, Gotoh M, Abrams P. ICIQ: a brief and robust measure for evaluating the symptoms and impact of urinary incontinence. Neurourology and Urodynamics 2004;23(4):322-30.

\section{Ayeleke 2013}

Ayeleke RO, Hay-Smith EJC, Omar MI. Pelvic floor muscle training added to another active treatment versus the same active treatment alone for urinary incontinence in women. Cochrane Database of Systematic Reviews 2013, Issue 11. [DOI: 10.1002/14651858.CD010551.pub2]

\section{Chen 1998}

Chen SS, Humphrey JD. Heat-induced changes in the mechanics of a collagenous tissue: pseudoelastic behavior at $37^{\circ} \mathrm{C}$. Journal of Biomechanics 1998;31(3):211-6.

\section{Cody 2012}

Cody JD, Jacobs ML, Richardson K, Moehrer B, Hextall A. Oestrogen therapy for urinary incontinence in post-menopausal women. Cochrane Database of Systematic Reviews 2012, Issue 10. [DOI: 10.1002/ 14651858.CD001405.pub3]

\section{Deeks 2011}

Deeks JJ, Higgins JPT, Altman DG (editors). Chapter 9. Analysing data and undertaking meta-analyses. In: Higgins JPT, Green S (editors). Cochrane Handbook for Systematic Reviews of Interventions Version 5.1.0 [updated March 2011]. The Cochrane Collaboration, 2011. www.cochranehandbook.org.

\section{Devereaux 2004}

Devereaux PJ, Choi PTL, El-Dika S, Bhandari M, Montori VM, Schünemann HJ, et al. An observational study found that authors of randomized controlled trials frequently use concealment of randomization and blinding, despite the failure to report these methods. Journal of Clinical

Epidemiology 2004;57(12):1232-6.

Dmochowski 2003

Dmochowski RR, Avon M, Ross J, Cooper JM, Kaplan R, Love $\mathrm{B}$, et al. Transvaginal radio frequency treatment of the endopelvic fascia: a prospective evaluation for the treatment of genuine stress urinary incontinence. Journal of Urology 2003;169(3):1028-32.

\section{Dumoulin 2014}

Dumoulin C, Hay-Smith EJC, Mac Habée-Séguin G. Pelvic floor muscle training versus no treatment, or inactive control treatments, for urinary incontinence in women. Cochrane Database of Systematic Reviews 2014, Issue 5. [DOI: 10.1002/14651858.CD005654.pub3]

\section{Fanelli 2003}

Fanelli RD, Gersin KS, Bakhsh A. The Stretta procedure: effective endoluminal therapy for GERD. Surgical Technology International 2003;11:129-34.

\section{Glazener 2001}

Glazener CMA, Cooper K. Anterior vaginal repair for urinary incontinence in women. Cochrane Database of Systematic Reviews 2001, Issue 1. [DOI: 10.1002/ 14651858.CD001755]

\section{Glazener 2014}

Glazener CMA, Cooper K. Bladder neck needle suspension for urinary incontinence in women. Cochrane Database of Systematic Reviews 2014, Issue 12. [DOI: 10.1002/ 14651858.CD003636.pub3]

\section{Guyatt 2008}

Guyatt GH, Oxman AD, Vist GE, Kunz R, Falck-Ytter Y, Schünemann HJ, et al. GRADE: what is "quality of evidence" and why is it important to clinicians?. BMJ (Clinical Research Ed.) 2008;336(7651):995-8.

\section{Guyatt 2011}

Guyatt G, Oxman AD, Akl EA, Kunz R, Vist G, Brozek $\mathrm{J}$, et al. GRADE guidelines: 1. Introduction-GRADE evidence profiles and summary of findings tables. Journal of Clinical Epidemiology 2011;64(4):383-94.

\section{Hampel 2004}

Hampel C, Artibani W, Espuña Pons M, Haab F, Jackson $\mathrm{S}$, Romero J, et al. Understanding the burden of stress urinary incontinence in Europe: a qualitative review of the literature. European Urology 2004;46(1):15-27.

Herbison 2013

Herbison GP, Dean N. Weighted vaginal cones for urinary incontinence. Cochrane Database of Systematic Reviews 2013, Issue 7. [DOI: 10.1002/14651858.CD002114.pub2]

Higgins 2002

Higgins JP, Thompson SG. Quantifying heterogeneity in a meta-analysis. Statistics in Medicine 2002;21(11):1539-58.

\section{Higgins 2003}

Higgins JP, Thompson SG, Deeks JJ, Altman DG. Measuring inconsistency in meta-analyses. BMJ (Clinical Research Ed.) 2003;327(7414):557-60. 
Higgins 2011a

Higgins JPT, Altman DG, Sterne JAC (editors). Chapter 8. Assessing risk of bias in included studies. In: Higgins JPT, Green S (editors). Cochrane Handbook for Systematic Reviews of Interventions. Version 5.1.0 [updated March 2011]. The Cochrane Collaboration, 2011. www.cochranehandbook.org.

Higgins 2011b

Higgins JPT, Green S (editors). Cochrane Handbook for Systematic Reviews of Interventions Version 5.1.0 [updated March 2011]. The Cochrane Collaboration, 2011. www.cochrane-handbook.org.

Higgins 2011c

Higgins JPT, Deeks JJ, Altman DG (editors). Chapter 16. Special topics in statistics. In: Higgins JPT, Green $S$ (editors). Cochrane Handbook for Systematic Reviews of Interventions. Version 5.1.0 [updated March 2011]. The Cochrane Collaboration, 2011. www.cochranehandbook.org.

Imamura 2010

Imamura M, Abrams P, Bain C, Buckley B, Cardozo L, Cody J, et al. Systematic review and economic modelling of the effectiveness and cost-effectiveness of non-surgical treatments for women with stress urinary incontinence.

Health Technology Assessment (Winchester, England) 2010;14 (40): 1-188.

\section{Karliner 2008}

Karliner L. Radiofrequency micro-remodeling for the treatment of female stress urinary incontinence. San Francisco (CA): California Technology Assessment Forum; 2008 October. ctaf.org/sites/default/files/assessments/ 930 ' file' Radiofrequency' for'SUI 'Wfinal.pdf (accessed 29 July 2014).

\section{Kirchin 2012}

Kirchin V, Page T, Keegan PE, Atiemo K, Cody JD, McClinton S. Urethral injection therapy for urinary incontinence in women. Cochrane Database of Systematic Reviews 2012, Issue 2. [DOI: 10.1002/ 14651858.CD003881.pub3]

Lapitan 2012

Lapitan MCM, Cody JD. Open retropubic colposuspension for urinary incontinence in women. Cochrane Database of Systematic Reviews 2012, Issue 6. [DOI: 10.1002/ 14651858.CD002912.pub5]

\section{Larson 2002}

Larson TR. Rationale and assessment of minimally invasive approaches to benign prostatic hyperplasia therapy. Urology 2002;59(2 Suppl 1):12-6.

Long 2008

Long RM, Giri SK, Flood HD. Current concepts in female stress urinary incontinence. Surgeon 2008;6(6):366-72.

\section{Lukban 2012b}

Lukban JC. Transurethral radiofrequency collagen denaturation for treatment of female stress urinary incontinence: a review of the literature and clinical recommendations. Obstetrics and Gynecology International 2012;2012:384234.

MacArthur 2006

MacArthur C, Glazener CM, Wilson PD, Lancashire RJ, Herbison GP, Grant AM. Persistent urinary incontinence and delivery mode history: a six-year longitudinal study. BJOG 2006;113(2):218-24.

\section{MacLennan 2000}

MacLennan AH, Taylor AW, Wilson DH, Wilson D. The prevalence of pelvic floor disorders and their relationship to gender, age, parity and mode of delivery. BJOG 2007;107 (12):1460-70.

\section{Mariappan 2005}

Mariappan P, Alhasso AA, Grant A, N'Dow JMO. Serotonin and noradrenaline reuptake inhibitors (SNRI) for stress urinary incontinence in adults. Cochrane Database of Systematic Reviews 2005, Issue 3. [DOI: 10.1002/ 14651858.CD004742.pub2]

\section{Miller 2007a}

Miller D. Office management of stress urinary incontinence: current and future role. Clinical Obstetrics and Gynecology 2007;50(2):376-82.

O'Connor 2011

O'Connor D, Green S, Higgins JPT (editors). Chapter 5. Defining the review question and developing criteria for including studies. In: Higgins JPT, Green $S$ (editors), Cochrane Handbook for Systematic Reviews of Interventions. Version 5.1.0 [updated March 2011]. The Cochrane Collaboration, 2011. www.cochranehandbook.org.

Ogah 2009

Ogah J, Cody JD, Rogerson L. Minimally invasive synthetic suburethral sling operations for stress urinary incontinence in women. Cochrane Database of Systematic Reviews 2009, Issue 4. [DOI: 10.1002/14651858.CD006375.pub2]

\section{Reference Manager 2012}

Reference Manager Professional Edition Version 12. New York: Thomson Reuters, 2012.

\section{Rehman 2011}

Rehman H, Bezerra CCB, Bruschini H, Cody JD. Traditional suburethral sling operations for urinary incontinence in women. Cochrane Database of Systematic Reviews 2011, Issue 1. [DOI: 10.1002/ 14651858.CD001754.pub3]

\section{RevMan 2014}

The Nordic Cochrane Centre, The Cochrane Collaboration. Review Manager (RevMan). 5.3. Copenhagen: The Nordic Cochrane Centre, The Cochrane Collaboration, 2014.

\section{Sand 2014a}

Sand PK, Owens GM, Black EJ, Anderson LH, Martinson MS. Cost effectiveness of radiofrequency microremodeling for stress urinary incontinence. International Urogynecology Journal 2014;25(4):517-23. 


\section{Schorge 2008}

Schorge JO, Schaffer JI, Halvorson LM, Hoffman BL, Bradshaw KD, Cunningham FG. Williams Gynecology. 1st Edition. New York: McGraw Hill, 2008.

\section{Schünemann 2011}

Schünemann HJ, Oxman AD, Vist GE, Higgins JPT, Deeks JJ, Glasziou P, et al. Chapter 12. Interpreting results and drawing conclusions. In: Higgins JPT, Green $S$ (editors). Cochrane Handbook for Systematic Reviews of Interventions Version 5.1.0 [updated March 2011]. The Cochrane Collaboration, 2011. www.cochranehandbook.org.

\section{Takacs 2010}

Takacs P, Nguyen A. Mechanism of action of the Renessa ${ }^{\circledR}$ treatment for stress urinary incontinence. http:// renessamd.com/wp-content/uploads/2010/10/MOAWhite-Paper.pdf (accessed 9 August 2011).

\section{Thom 1997}

Thom DH, van den Eeden SK, Brown JS. Evaluation of parturition and other reproductive variables as risk factors for urinary incontinence in later life. Obstetrics and Gynecology 1997;90(6):983-9.

\section{Wallace 2004}

Wallace SA, Roe B, Williams K, Palmer M. Bladder training for urinary incontinence in adults. Cochrane Database of Systematic Reviews 2004, Issue 1. [DOI: 10.1002/ 14651858.CD001308.pub2]

Ware 1993

Ware JE, Snow KK, Kosinski M, Gandek B. SF-36 Health survey manual and interpretation guide. Boston, MA: The Health Institute, New England Medical Centre, 1993.

\section{Wright 2002}

Wright NT, Humphrey JD. Denaturation of collagen via heating: an irreversible rate process. Annual Review of Biomedical Engineering 2002;4:109-28.

\section{References to other published versions of this review}

\section{Dahm 2012}

Dahm P, Kang D, Han J, Neuberger MM, Moy ML, Alonso-Coello P. Transurethral radiofrequency collagen denaturation for the treatment of stress urinary incontinence in women. Cochrane Database of Systematic Reviews 2012, Issue 11. [DOI: 10.1002/14651858.CD010217]

* Indicates the major publication for the study 


\title{
CHARACTERISTICS OF STUDIES
}

\section{Characteristics of included studies [ordered by study ID]}

\author{
Appell 2006
}

Methods Study design: parallel-group, sham-controlled randomised trial; 2:1 randomisation Study dates: Participants were reported to have been enrolled between March 2003 and September 2003 in the primary study publication; however, these dates were reported as March 2002 to September 2002 in 2 related articles; length of follow-up = 12 months Setting: multi-centre trial performed at 10 sites in the United States

Participants

Inclusion criteria: SUI diagnosed by patient history and witnessed SUI on physical exam, bladder outlet hypermobility on physical exam and baseline leak point pressure $\geq 60$ $\mathrm{cm} \mathrm{H}_{2} \mathrm{O}$

Exclusion criteria: evidence of detrusor overactivity on cystometrogram, post-void residual $>50 \mathrm{cc}$, history of dry or wet overactive bladder, previous surgery or bulking agent therapy and significant stage IV pelvic organ prolapse

Sample size: 173 participants enrolled

Age: mean 50 years (range 22 to 76 years)

UI duration: mean 8 years (range 1 to 49 years)

Note: Women with a change in medical condition such as hysterectomy or urinary tract infection were excluded from the final analysis of incontinence quality of IIfe at 12 months

Interventions

Transurethral radiofrequency collagen denaturation $(\mathrm{n}=110)$ : A 21 French transurethral micro-remodeling probe was used and was connected to a radiofrequency generator. All participants were treated with the same type of radiofrequency probe (Novasys Medical, Inc., Newark, California) and 1 of 2 similar types of radiofrequency generator (Novasys Medical, Inc.; Curon Medical, Inc., Fremont, California). After passage into the bladder, a balloon on the probe tip was insufflated to anchor the probe within the bladder outlet. Four 23-gauge needle electrodes were deployed into the urethral submucosa, and radiofrequency was delivered for 60-second intervals. The probe was rotated after each interval until the needles were placed in 9 different positions within the urethra ( 9 minutes total)

Sham treatment $(n=63)$ : Sham treatment also utilised a transurethral probe; however the probe lacked needle electrodes, and the radiofrequency generator was modified so no energy was delivered but the generator appeared and sounded as though energy were being delivered

\section{Serious adverse events}

How measured: All adverse events were recorded; no definition of 'serious adverse event' was provided

Time points measured: at 1 week, 1 month, 3 months, 6 months and 12 months

Time points reported: 12-month prevalence

Subgroups: no subgroups reported

Disease-specific quality of life

How measured: 10-Point or greater improvement in Incontinence Quality of Life (IQOL) score

Time points measured: at 6 months and at 12 months 
Time points reported: at 12 months

Subgroups: post hoc subgroup analysis according to level of UI at baseline (mild vs moderate to severe)

Clinician observations: objective measurement of incontinence: change in leak point pressure

How measured: mean change in leak point pressure testing

Time points measured: at 6 months and at 12 months

Time points reported: at 12 months

Subgroups: no subgroups reported

Surgical outcome measures: other surgical outcome measures reported by individual trials: level of postoperative discomfort

How measured: participant-reported level of postoperative discomfort as assessed on a visual analogue scale from 0 (no pain) to 10 (terrible pain)

Time points measured: immediately before discharge

Time points reported: immediately before discharge; however, no data were reported for the sham treatment group except that the mean was not statistically significantly different from that of the transurethral radiofrequency collagen denaturation group Subgroups: No subgroups were reported

Other adverse events: pain/dysuria

How measured: dysuria - all adverse events were recorded

Time points measured: at 1 week, 1 month, 3 months, 6 months and 12 months

Time points reported: 12 -month prevalence

Subgroups: no subgroups reported

Other adverse events: (new) detrusor overactivity: overactive bladder symptoms

How measured: All adverse events were recorded

Time points measured: at 1 week, 1 month, 3 months, 6 months and 12 months

Time points reported: 12-month prevalence

Subgroups: No subgroups were reported

Note: Dry overactive bladder and wet overactive bladder data were reported separately in the study; however in the review we combined the numbers of events to assess the outcome overactive bladder symptoms

Other adverse events: de novo urinary retention

How measured: All adverse events were recorded

Time points measured: at 1 week, 1 month, 3 months, 6 months and 12 months

Time points reported: 12 -month prevalence

Subgroups: No subgroups were reported

Note: unclear whether the events reported were of new onset

Other adverse events: urinary tract infection

How measured: All adverse events were recorded

Time points measured: at 1 week, 1 month, 3 months, 6 months and 12 months

Time points reported: 12 -month prevalence

Subgroups: No subgroups were reported

Other adverse events: haematuria

How measured: All adverse events were recorded

Time points measured: at 1 week, 1 month, 3 months, 6 months and 12 months

Time points reported: 12 -month prevalence

Subgroups: No subgroups were reported

Other adverse events: other adverse events reported by individual trials: hesitancy

Transurethral radiofrequency collagen denaturation for the treatment of women with urinary incontinence (Review) 
How measured: All adverse events were recorded

Time points measured: at 1 week, 1 month, 3 months, 6 months and 12 months

Time points reported: 12 -month prevalence

Subgroups: No subgroups were reported

\begin{tabular}{l|l}
\hline Funding Source & Grant sponsored by Novasys Medical, Inc \\
\hline Declarations of Interest & No conflicts of interest were reported by study authors \\
\hline Notes & \\
\hline
\end{tabular}

Risk of bias

\begin{tabular}{l|l|l}
\hline Bias & Authors' judgement & Support for judgement \\
\hline $\begin{array}{l}\text { Random sequence generation (selection } \\
\text { bias) }\end{array}$ & Low risk & $\begin{array}{l}\text { Quote: "Subjects were prospectively ran- } \\
\text { domized" } \\
\text { Quote: "Computer-generated randomiza- } \\
\text { tion targeted a 2:1 treatment to sham treat- } \\
\text { ment arm ratio" } \\
\text { Comment: Computer randomisation was } \\
\text { used and was found to be adequate }\end{array}$ \\
\hline Allocation concealment (selection bias) & Unclear risk & $\begin{array}{l}\text { Comment: Allocation concealment was } \\
\text { not reported }\end{array}$
\end{tabular}

Blinding of participants and personnel Unclear risk (performance bias)

Subjective outcomes

Quote: "Subjects [...] remained blinded through the 12 months duration of the trial"

Quote: "the sham treatment RF generator was modified so that no RF was actually delivered, although the generator appeared and sounded as if RF was being delivered" Comment: Participants were blinded as to whether they received treatment or sham treatment, but blinding of study personnel was unclear

Blinding of participants and personnel Unclear risk (performance bias)

Objective outcomes

Quote: “Subjects [...] remained blinded through the 12 months duration of the trial”

Quote: "the sham treatment RF generator was modified so that no RF was actually delivered, although the generator appeared and sounded as if RF was being delivered" Comment: Participants were blinded as to whether they received treatment or sham treatment, but blinding of study personnel was unclear 
Appell 2006 (Continued)

Blinding of outcome assessment (detection Unclear risk bias)

Subjective outcomes

Blinding of outcome assessment (detection Low risk

bias)

Objective outcomes

Incomplete outcome data (attrition bias) High risk Disease-specific quality of life
Comment: It was unclear whether outcome assessors were blinded
Comment: Although blinding of outcome assessors was unclear, risk of bias for objective outcomes was judged as low

Quote: “At 12 months, the evaluable population for the quality of life outcome analysis included 142 women ( $82 \%$ of enrolled) , 89 in the treatment $(80.1 \%)$ and 53 in the sham treatment $(84.1 \%)$ arm $(1.7: 1$ ratio). The two evaluable population arms did not statistically significantly differ for mean age, mean SUI duration, mean body mass index, menopausal status, mean baseline LPP, or mean baseline I-QOL score. Analysis did not include 12 months I-QOL data from 21 women who were lost to follow-up, 8 women whose change in I-QOL (either favorable or unfavorable) could not clearly be attributed to the treatment or sham treatment due to a change in medical history (hysterectomy during the trial period, urinary tract infection at 12 months, etc.), and two women whose baseline IQOL scores were $>90$ points and who, therefore, could not numerically achieve $\geq$ 10 point score improvement" Comment: For the I-QOL outcome, 21 of $110(19.1 \%)$ and 10 of $63(15.9 \%)$ participants in the treatment and control arms, respectively, were lost to follow-up or were otherwise considered unevaluable and were excluded from analysis. Although these percentages were similar across groups, it was unclear whether the reasons for missing data were balanced across groups. Risk of bias was judged to be high

Incomplete outcome data (attrition bias) Objective measurement of incontinence
High risk

Quote: "At 12 months, the evaluable population for the LPP analysis included 136 women (78.6\% of enrolled), 87 in the treatment $(79.1 \%)$ and 49 in the sham treatment $(77.8 \%)$ arm (1.8:1 ratio). The two evaluable population arms did not statistically significantly differ for mean age, 
Appell 2006 (Continued)

mean SUI duration, mean body mass index, menopausal status, mean baseline IQOL score, or mean baseline LPP. Analysis did not include 12 months LPP data from 21 women who were lost to followup, 6 women whose change in LPP (either increase or decrease) could not clearly be attributed to the treatment or sham treatment due to a change in medical history (such as the performance of a hysterectomy during the trial period), and 10 women whose LPP performance parameters violated trial protocol guidelines"

Comment: For the LPP assessment, 23 of $110(20.9 \%)$ and 14 of $63(22.2 \%)$ participants in the treatment and control arms, respectively, were lost to follow-up or were otherwise considered unevaluable and were excluded from analysis. Although these percentages were similar across groups, it was unclear whether the reasons for missing data were balanced across groups. Risk of bias was judged to be high

Incomplete outcome data (attrition bias) Serious adverse events; other surgical outcome measures reported by individual trials; other adverse events
Unclear risk

Comment: We judged the completeness of outcomes data for these outcomes to be unclear. Participants were lost to followup or were otherwise considered unevaluable and were excluded from analysis of other outcomes; therefore outcomes data may have also been incomplete for serious adverse events, other surgical outcome measures and other adverse event outcomes
Comment: Outcomes at 6 months of follow-up were not reported. For the postoperative level of discomfort outcome, data were reported for the RF treatment group but not for the sham treatment group, although the study authors reported no statistically significant differences between groups

Comment: Investigators reported a post hoc subgroup analysis that grouped participants according to their baseline degree of incontinence as 'mild' versus 'moderate to severe'. Results of this subgroup analysis were judged to be at high risk of bias 
$\mathrm{I}-\mathrm{QOL}$ = Incontinence Quality of Life; LPP = leak point pressure; RF = radiofrequency; SUI = stress urinary incontinence; UI = urinary incontinence.

Characteristics of excluded studies [ordered by study ID]

\begin{tabular}{|c|c|}
\hline Study & Reason for exclusion \\
\hline Appell 2007 & Not a randomised or quasi-randomised trial; a review paper \\
\hline Appell 2008 & Not a randomised or quasi-randomised trial; a review paper \\
\hline Crivellaro 2009 & Not a randomised or quasi-randomised trial; a review paper \\
\hline Davila 2011 & Not a randomised or quasi-randomised trial; a review paper \\
\hline Dillon 2009 & Not a randomised or quasi-randomised trial; a review paper \\
\hline Dmochowski 2002 & Not a randomised or quasi-randomised trial; a review paper \\
\hline Edelstein 2006 & Non-human participants \\
\hline Elser 2007 & Not a randomised or quasi-randomised trial; a review paper \\
\hline Elser 2009 & $\begin{array}{l}\text { Not a randomised or quasi-randomised trial; } 12 \text {-month, } 18 \text {-month and 36-month follow-up results from a } \\
\text { prospective, 36-month, open-label, single-arm clinical trial }\end{array}$ \\
\hline Gilleran 2005 & Not a randomised or quasi-randomised trial; a review paper \\
\hline Juma 2007 & Not a randomised or quasi-randomised trial; a review paper \\
\hline Lenihan 2005 & $\begin{array}{l}\text { Not a randomised or quasi-randomised trial; an open-label pilot clinical trial looking at the use of oral plus } \\
\text { local anaesthesia while transurethral radiofrequency collagen denaturation is performed in an office setting }\end{array}$ \\
\hline Lukban $2012 \mathrm{a}$ & Not a randomised or quasi-randomised trial; a review paper \\
\hline Lukban 2013a & $\begin{array}{l}\text { Not a randomised or quasi-randomised trial; a single-arm prospective multi-centre trial; } 6 \text {-month and } 12 \text { - } \\
\text { month follow-up reported of projected } 36 \text {-month follow-up (ongoing) }\end{array}$ \\
\hline Lukban $2013 b$ & Not a randomised or quasi-randomised trial; a review paper \\
\hline Miller 2007b & Not a randomised or quasi-randomised trial; a review paper \\
\hline Sand $2014 b$ & Not a randomised or quasi-randomised trial; a cost analysis of treatment \\
\hline Sotomayor 2003 & $\begin{array}{l}\text { Not a randomised or quasi-randomised trial. Pilot clinical trial comparing } 6 \text {-month and } 12 \text {-month outcomes of } \\
4 \text { radiofrequency collagen denaturation treatment regimens, which differed in total numbers of radiofrequency } \\
\text { micro-remodeling sites and anatomical locations }\end{array}$ \\
\hline
\end{tabular}

Transurethral radiofrequency collagen denaturation for the treatment of women with urinary incontinence (Review) 
(Continued)

Takacs $2013 \quad$ Not a randomised or quasi-randomised trial; a review paper

Vianello $2007 \quad$ Not a randomised or quasi-randomised trial; a review paper

Wells $2007 \quad$ Not a randomised or quasi-randomised trial; a single-arm multi-centre trial evaluating the feasibility, safety and efficacy of oral sedation and a local anaesthetic regimen in performing radiofrequency collagen denaturation 
DATA ANDANALYSES

Comparison 1. Transurethral radiofrequency collagen denaturation versus no treatment/sham treatment

Outcome or subgroup title No. of No. of

studies participants

Statistical method

Effect size

1 Serious adverse events

1 Risk Ratio (M-H, Random, 95\% CI)

Totals not selected

2 Disease-specific quality of life:

Risk Ratio (M-H, Random, 95\% CI)

Totals not selected

number of women with an

I-QOL score improvement $\geq$

10 points at 12 months

3 Clinician observations: objective measurement of incontinence:

change in leak point pressure at

12 months

4 Other adverse event:

pain/dysuria: dysuria

5 Other adverse event: (new)

1

detrusor overactivity: overactive bladder symptoms

6 Other adverse event: de novo urinary retention: urinary retention

7 Other adverse event: urinary tract infection

8 Other adverse event: haematuria

9 Other adverse event: hesitancy

1

1

1

1

1
Risk Ratio (M-H, Random, 95\% CI)

Risk Ratio (M-H, Random, 95\% CI)

Risk Ratio (M-H, Random, 95\% CI)

Risk Ratio (M-H, Random, 95\% CI)

Risk Ratio (M-H, Random, 95\% CI)

Risk Ratio (M-H, Random, 95\% CI)
Totals not selected

Totals not selected

Totals not selected

Totals not selected

Totals not selected

Totals not selected

\section{Analysis I.I. Comparison I Transurethral radiofrequency collagen denaturation versus no treatment/sham treatment, Outcome I Serious adverse events.}

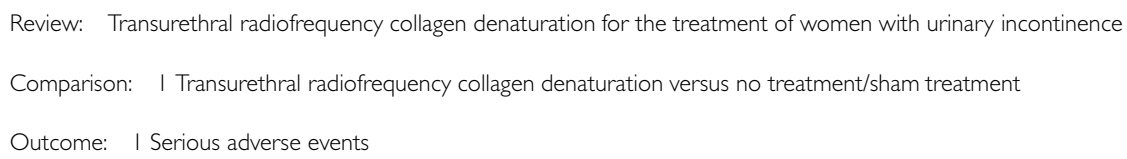

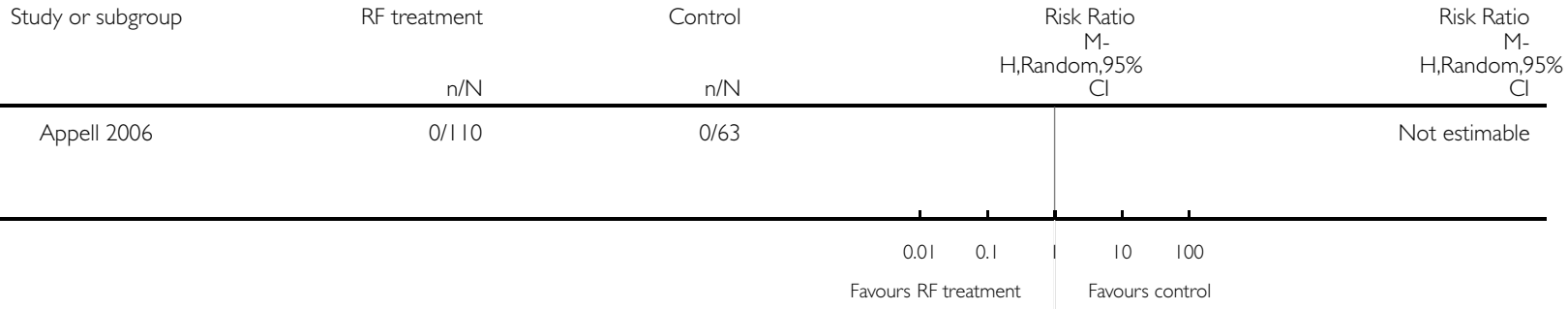


Analysis I.2. Comparison I Transurethral radiofrequency collagen denaturation versus no treatment/sham treatment, Outcome 2 Disease-specific quality of life: number of women with an I-QOL score improvement $\geq$ 10 points at 12 months.

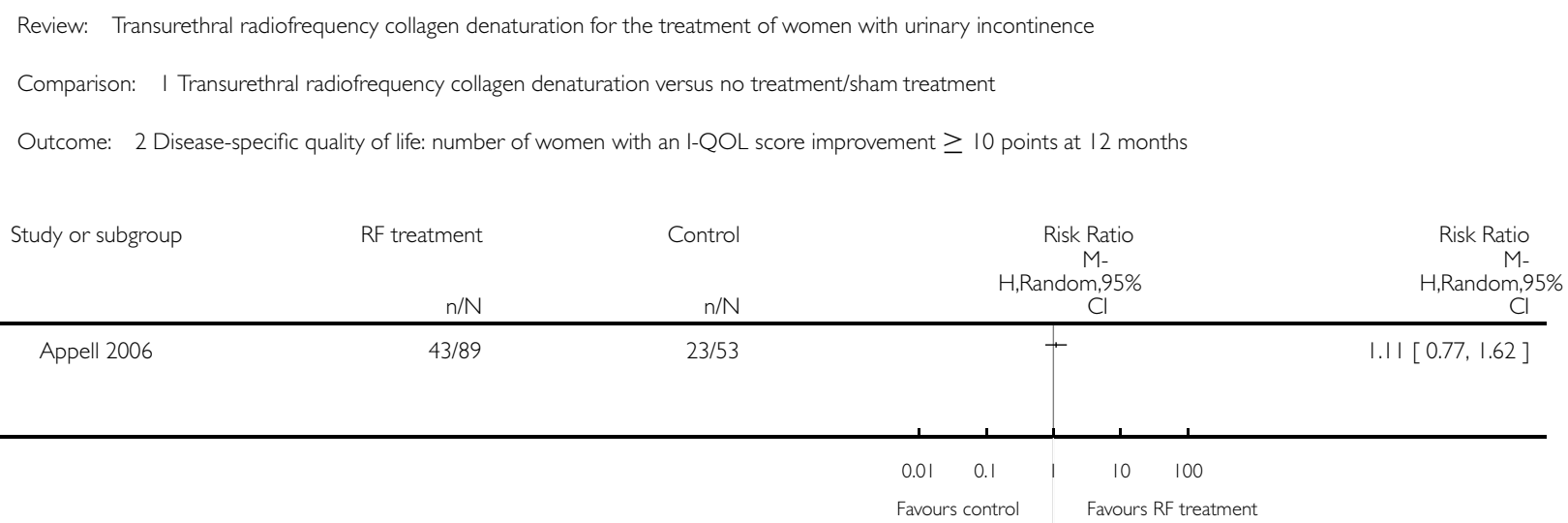

Analysis I.3. Comparison I Transurethral radiofrequency collagen denaturation versus no treatment/sham treatment, Outcome 3 Clinician observations: objective measurement of incontinence: change in leak point pressure at 12 months.

Review: Transurethral radiofrequency collagen denaturation for the treatment of women with urinary incontinence

Comparison: I Transurethral radiofrequency collagen denaturation versus no treatment/sham treatment

Outcome: 3 Clinician observations: objective measurement of incontinence: change in leak point pressure at 12 months

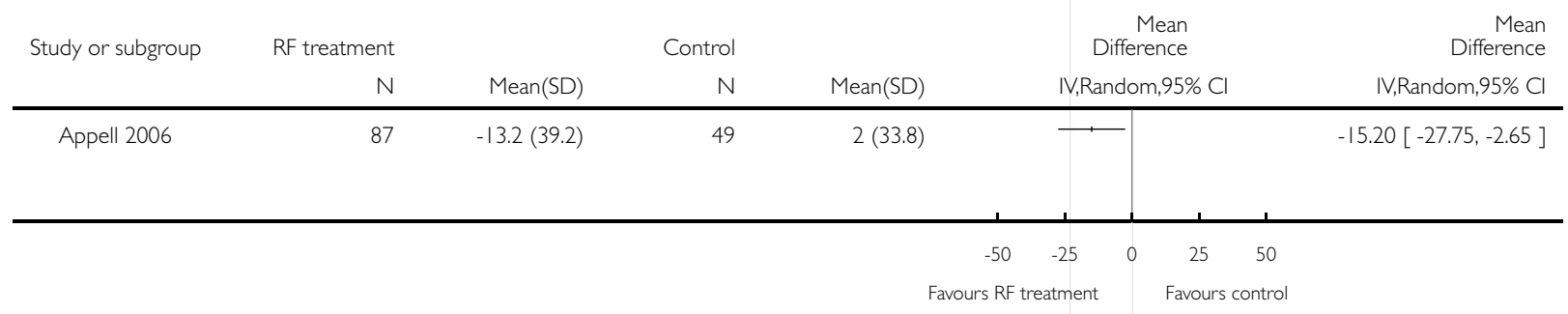

Transurethral radiofrequency collagen denaturation for the treatment of women with urinary incontinence (Review) 


\section{Analysis I.4. Comparison I Transurethral radiofrequency collagen denaturation versus no treatment/sham treatment, Outcome 4 Other adverse event: pain/dysuria: dysuria.}

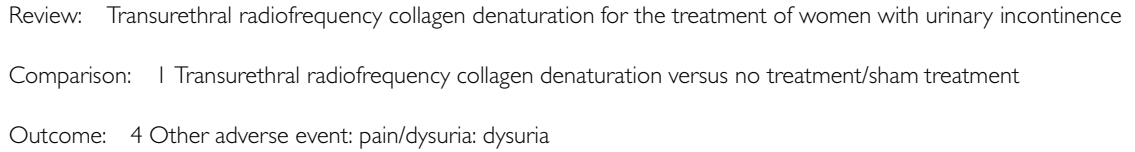

$n / N \quad n / N$

$1 / 63$

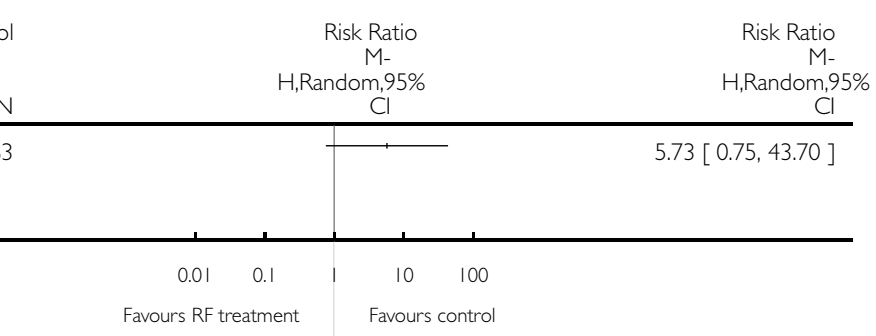

Analysis I.5. Comparison I Transurethral radiofrequency collagen denaturation versus no treatment/sham treatment, Outcome 5 Other adverse event: (new) detrusor overactivity: overactive bladder symptoms.

Review: Transurethral radiofrequency collagen denaturation for the treatment of women with urinary incontinence

Comparison: I Transurethral radiofrequency collagen denaturation versus no treatment/sham treatment

Outcome: 5 Other adverse event: (new) detrusor overactivity: overactive bladder symptoms

Study or subgroup $\quad$ RF treatment $\quad$ Control Risk Ratio Ratio

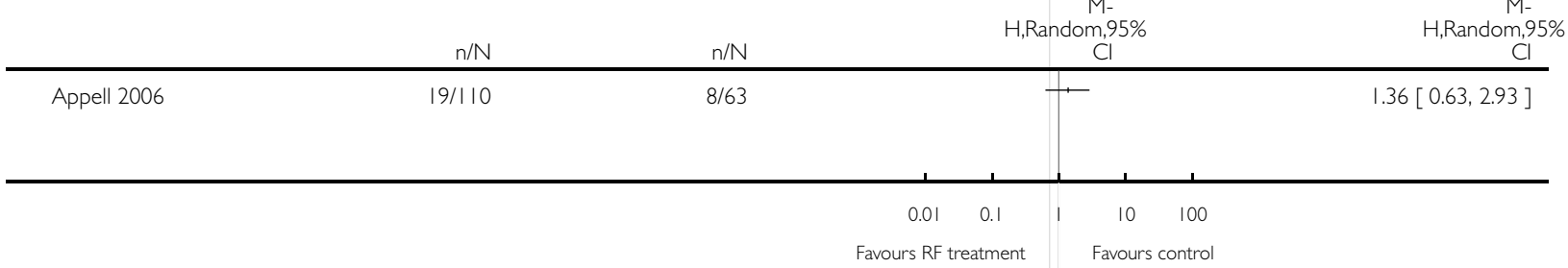


Analysis I.6. Comparison I Transurethral radiofrequency collagen denaturation versus no treatment/sham treatment, Outcome 6 Other adverse event: de novo urinary retention: urinary retention.

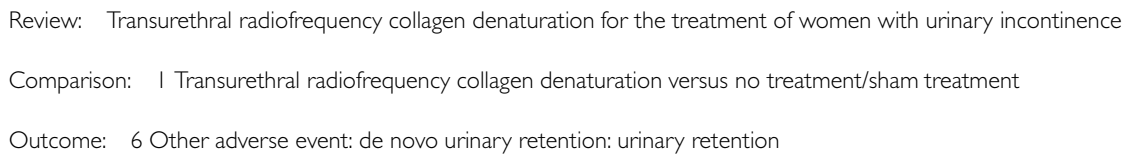

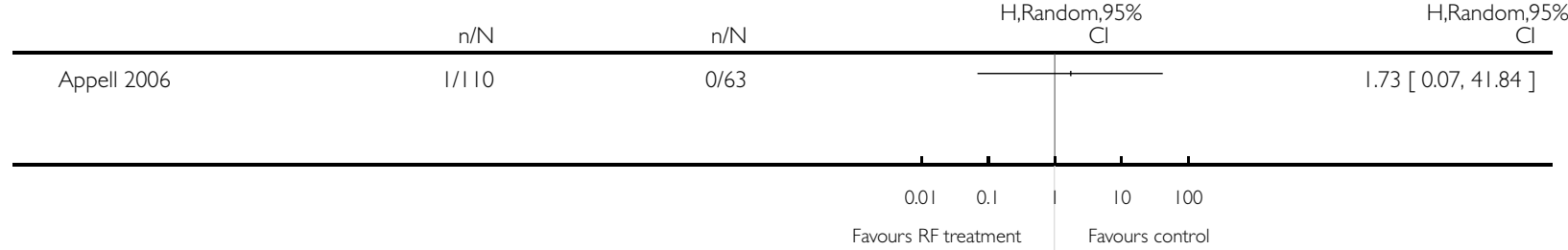

Analysis I.7. Comparison I Transurethral radiofrequency collagen denaturation versus no treatment/sham treatment, Outcome 7 Other adverse event: urinary tract infection.

Review: Transurethral radiofrequency collagen denaturation for the treatment of women with urinary incontinence

Comparison: I Transurethral radiofrequency collagen denaturation versus no treatment/sham treatment

Outcome: 7 Other adverse event: urinary tract infection

\begin{tabular}{lcc} 
& $\mathrm{n} / \mathrm{N}$ & $\mathrm{n} / \mathrm{N}$ \\
\hline Appell 2006 & $5 / 110$ & $3 / 63$
\end{tabular}

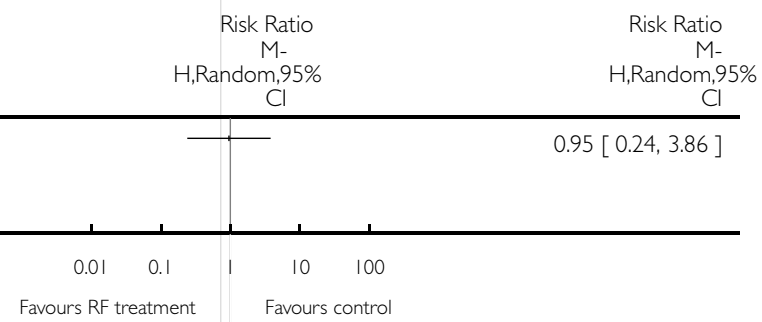


Analysis I.8. Comparison I Transurethral radiofrequency collagen denaturation versus no treatment/sham treatment, Outcome 8 Other adverse event: haematuria.

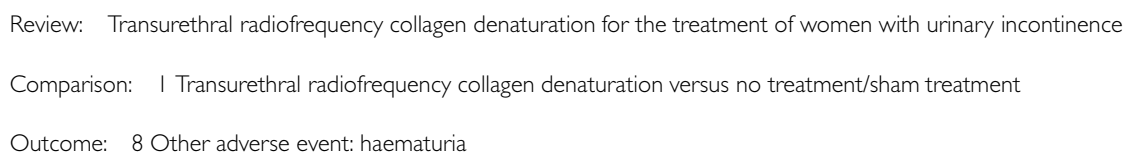

$0 / 63$

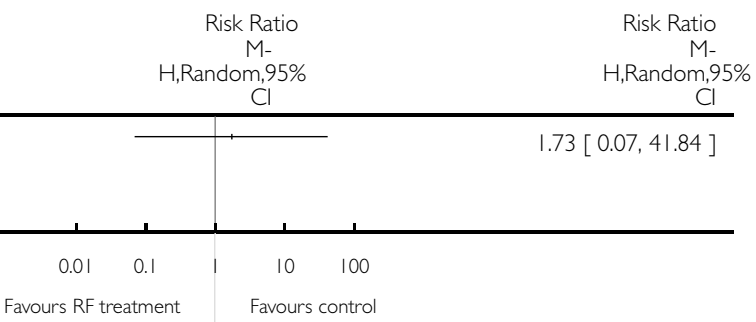

\section{Analysis 1.9. Comparison I Transurethral radiofrequency collagen denaturation versus no treatment/sham treatment, Outcome 9 Other adverse event: hesitancy.}

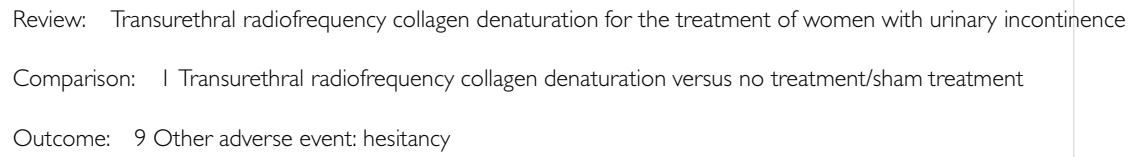

$1 / 63$




\section{A P P E N D I C E S}

\section{Appendix I. Search strategy - Cochrane Incontinence Group Specialised Register}

This review drew on the search strategy developed for the Cochrane Incontinence Group. We identified relevant trials from the Cochrane Incontinence Group Specialised Trials Register. For more details of the search methods used to build the Specialised Register, please see the Group's module in The Cochrane Library. The Register contains trials identified from the Cochrane Central Register of Controlled Trials (CENTRAL), MEDLINE and MEDLINE in process, ClinicalTrials.gov and WHO ICTRP and by handsearching of journals and conference proceedings. Most of the trials in the Cochrane Incontinence Group Specialised Register are also contained in CENTRAL. The date of the last search was 19 December 2014.

The terms used to search the Incontinence Group Specialised Register are given below.

$\left(\left(\left\{\right.\right.\right.$ DESIGN.CCT $\left.{ }^{*}\right\} \quad$ OR $\quad\{$ DESIGN.RCT* $\left.\}\right) \quad$ AND $\quad\left(\left\{\right.\right.$ INTVENT.SURG.RadioFreq* ${ }^{*} \quad$ OR

\{INTVENT.SURG.transurethralMicrowave*\}) AND \{TOPIC.URINE.INCON*\})

(All searches were of the keyword field of Reference Manager 2012.)

\section{Appendix 2. Search strategy - EMBASE via Ovid SP}

On 19 December 2014, EMBASE and EMBASE Classic were searched (1947 to 2014 Week 50) using the following strategy.

1. randomized controlled trial/

2. controlled study/

3. clinical study/

4. major clinical study/

5. prospective study/

6. meta analysis/

7. exp clinical trial/

8. randomization/

9. crossover procedure/ or double blind procedure/ or parallel design/ or single blind procedure/

10. placebo/

11. latin square design/

12. exp comparative study/

13. follow up/

14. pilot study/

15. family study/ or feasibility study/or pilot study/or study/

16. placebo $\$ . t w$.

17. random\$.tw.

18. (clin\$ adj25 trial\$).tw.

19. ( (singl\$ or doubl\$ or trebl\$ or tripl\$) adj25 (blind $\$$ or mask $\$)$ ).tw.

20. factorial.tw.

21. crossover.tw.

22. latin square.tw.

23. (balance $\$$ adj2 block\$).tw.

24. factorial design/

25. parallel design/

26. triple blind procedure/

27. community trial/

28. intervention study/

29. experimental study/

30. prevention study/

31. quasi experimental study/

32. or/1-31

33. (nonhuman not human).sh.

34. 32 not 33

35. incontinence/ or mixed incontinence/ or stress incontinence/ or urge incontinence/ or urine incontinence/

Transurethral radiofrequency collagen denaturation for the treatment of women with urinary incontinence (Review)

Copyright $\Subset 2015$ The Cochrane Collaboration. Published by John Wiley \& Sons, Ltd. 
36. continence/

37. overactive bladder/

38. micturition disorder/ or lower urinary tract symptom/ or pollakisuria/

39. urinary dysfunction/ or bladder instability/ or detrusor dyssynergia/ or neurogenic bladder/ or urinary urgency/ or urine extravasation/

40. (incontinen\$ or continen\$).tw.

41. ((bladder or detrusor or vesic\$) adj5 (instab\$ or stab\$ or unstab* or irritab\$ or hyperreflexi\$ or dys?ynerg\$ or dyskinesi\$ or irritat\$)).tw.

42. (urin\$ adj2 leak\$).tw.

43. ((bladder or detrusor or vesic $\$$ ) adj2 (hyper $\$$ or overactiv $\$)$ ).tw.

44. (bladder\$ adj2 (neuropath\$ or neurogen* or neurolog $\$$ )).tw.

45. (nervous adj pollakisur\$).tw.

46.35 or 36 or 37 or 38 or 39 or 40 or 41 or 42 or 43 or 44 or 45

47. catheter ablation/

48. radiofrequency ablation/

49. radiofrequency/

50. pulsed radiofrequency treatment/

51. radiofrequency radiation/

52. (radiofrequenc $\$$ adj 4 remodel $\$$ ).tw.

53. (radiofrequenc $\$$ adj4 denatur\$).tw.

54. (transurethral adj2 radiofrequenc\$).tw.

55. $(\mathrm{rf}$ adj 4 remodel\$).tw.

56. renessa.tw.

57. lyrette.tw

58.47 or 48 or 49 or 50 or 51 or 52 or 53 or 54 or 55 or 56 or 57

59.34 and 46 and 58

\section{Appendix 3. Search strategy - Google Scholar}

(lyrette OR renessa OR transurethral collagen denaturation OR radiofrequency collagen denaturation OR radiofrequency collagen remodeling OR transurethral collagen remodeling) AND stress urinary incontinence

The date of the last search was 19 December 2014.

\section{Appendix 4. Search strategy - FDA website}

renessa OR radiofrequency transurethral OR lyrette

The date of the last search was 19 December 2014.

\section{Appendix 5. Search strategy - Current Controlled Trials}

stress urinary incontinence

The date of the last search was 19 December 2014. 


\section{Appendix 6. Search strategy - ClinicalTrials.gov}

1. SUI AND (transurethral OR collagen OR denaturation OR remodeling)

2. stress urinary incontinence AND (transurethral OR collagen OR denaturation OR remodeling)

3. lyrette OR renessa

The date of the last search was 19 December 2014.

\section{Appendix 7. Search strategy - WHO ICTRP}

(SUI OR stress urinary incontinence) AND transurethral

The date of the last search was 19 December 2014.

\section{CONTRIBUTIONSOFAUTHORS}

Philipp Dahm (PD), Diana Kang (DK) and Julia Han (JH) were responsible for the conception of the review protocol.

Sheila A Wallace (SAW) provided searching expertise. SAW, PD, DK, JH and M Louis Moy (MLM) were responsible for developing the search strategy. SAW, DK and JH were responsible for undertaking searches. DK, JH and Molly M Neuberger (MMN) were responsible for obtaining copies of trials. $\mathrm{PD}, \mathrm{DK}$ and $\mathrm{JH}$ were responsible for screening search results, screening retrieved papers against the inclusion criteria and appraising the quality of papers. DK and JH were responsible for extracting data.

MMN was responsible for entering data into Review Manager.

$\mathrm{DK}, \mathrm{JH}$ and $\mathrm{MMN}$ were responsible for carrying out the analysis. PD and MMN were responsible for rating the quality of the evidence and preparing the 'Summary of findings' table. PD, DK and JH were responsible for interpreting the analysis.

PD, MLM, DK and JH were responsible for drafting and updating the final review.

Pablo Alonso-Coello (PA) and MMN were responsible for reviewing the protocol and the final review. PA also provided methodological expertise.

\section{DECLARATIONSOF INTEREST}

D Kang: none known.

J Han: none known.

MM Neuberger: none known.

ML Moy: none known.

SA Wallace: none known.

P Alonso-Coello: none known.

P Dahm: none known. 


\title{
SOURCES OF SUPPORT
}

\author{
Internal sources \\ - Department of Urology, College of Medicine, University of Florida, USA. \\ - Urology Section, Minneapolis VA Health Care System, Department of Veterans Affairs, USA.
}

\section{External sources}

- Dennis W. Jahnigen Career Development Scholars Award by the American Geriatrics Society, USA.

- The National Institute for Health Research (NIHR), UK.

The National Institute for Health Research (NIHR) is the largest single funder of the Cochrane Incontinence Group.

\section{DIFFERENCES BETWEEN PROTOCOLANDREVIEW}

This review is based on a published protocol (Dahm 2012), with differences as described here.

The focus of the review was broadened from 'stress urinary incontinence' to 'urinary incontinence' in accordance with editorial and peer referee feedback.

In the Methods section 'Types of studies', we clarified that we included parallel-group trials and excluded cluster-randomised and crossover trials for consistency with the 'Unit of analysis issues' section of the protocol.

In the Methods section 'Types of outcome measures', we clarified that measurement of outcomes assessed in this review was not a criterion for inclusion. We rephrased the primary outcome 'Participant-reported measures: number of women reporting urinary incontinence symptoms after transurethral collagen denaturation at time points defined by investigators' to be applicable to all interventions assessed in the review; now phrased as 'Participant-reported measures: number of women reporting UI symptoms after intervention at time points defined by investigators'. In accordance with current recommendations that primary outcomes include at least one potential benefit and at least one potential harm (O'Connor 2011), we added two primary outcomes that had been classified among the secondary outcomes in the protocol; these are 'Disease-specific quality of life: disease-specific quality of life assessed through validated measures' and 'Serious adverse events: major vascular or visceral injury, bladder/urethral perforation, nerve damage, fistula formation or other major surgical complications'. To accommodate these changes to the primary outcomes, we made the following changes to the secondary outcomes of the review: removed the patient observations outcome 'Number of women with SUI not improved symptomatically as reported by patient questionnaire, e.g. Incontinence Quality of Life (I-QOL) questionnaire, or other patient observations as reported by individual trials'; changed the 'Quality of life' outcome heading to 'Other quality of life'; removed the quality of life outcome 'Condition-specific health measures (specific instruments designed to assess incontinence)'; changed the 'Adverse events' outcome heading to 'Other adverse events'; removed the adverse events outcomes 'Major vascular or visceral injury', 'Bladder or urethral perforation', 'Nerve damage', 'Other perioperative surgical complications', 'De novo urge symptoms or urge incontinence' and 'Erosion or fistula to vagina'; changed the adverse events outcome 'Other serious adverse events reported by individual trials' to 'Other adverse events reported by individual trials'. We also removed the quantification of symptoms secondary outcome 'Incontinence episodes' due to overlap with other outcomes. In response to editorial and peer referee feedback, we changed the classification of the 'Repeat continence surgery' outcome from the 'Other adverse events' outcome heading to instead represent a separate outcome heading and outcome, 'Repeat continence surgery: number of women undergoing repeat continence surgery'. Additionally, we added the subheading 'Main outcomes for 'Summary of findings table" and listed there the outcomes included in the 'Summary of findings' table, as the main outcomes were not specified in the protocol.

In the Methods section 'Data extraction and management', we clarified that data abstraction was performed independently by two review authors. We also added the following statement to clarify the specific data extracted: "Extracted data included study design; dates when the study was conducted; setting; participant inclusion and exclusion criteria; participant age; sample size of the study and of each intervention group; details of interventions; details of outcomes relevant to the review including how measured, time points at which they were measured and outcomes data; details of funding sources; declarations of interest among primary study authors; and study details relevant to risk of bias assessment."

Transurethral radiofrequency collagen denaturation for the treatment of women with urinary incontinence (Review)

Copyright @ 2015 The Cochrane Collaboration. Published by John Wiley \& Sons, Ltd. 
In the Methods section 'Assessment of risk of bias in included studies', we updated the risk of bias judgements to 'low', 'unclear' or 'high' risk of bias and updated the risk of bias domain names for consistency with the current version of tool for assessing risk of bias of The Cochrane Collaboration (Higgins 2011a). We also clarified that each risk of bias for blinding of participants and personnel, blinding of outcome assessment and incomplete outcome data was assessed on an outcome-specific basis.

We expanded the Methods section 'Measures of treatment effect' to clarify the data that we sought and used to calculate the stated measures of treatment effect.

In the Methods section 'Unit of analysis issues', we clarified that no studies with multiple intervention groups were identified although they were eligible for inclusion.

In the protocol we had planned to analyse all data by intention-to-treat analysis, imputing missing data with replacement values. However, in the review we based analyses on available data only and addressed missing data in the risk of bias assessment in accordance with guidance provided in the Cochrane Handbook for Systematic Reviews of Interventions (Higgins 2011c). We revised the Methods section 'Dealing with missing data' to reflect this change.

As only one study was included in the review, it was neither necessary to assess heterogeneity nor to test for funnel plot asymmetry to assess potential publication bias, as we had planned in the protocol.

We attempted to obtain study protocols to assess for reporting bias in accordance with Cochrane standards, and we added a statement to the Methods section 'Assessment of reporting biases' to reflect this.

In the protocol, we planned to pool data from eligible studies in a meta-analysis, but this was not possible as only one study was included in the review. We also clarified the meta-analysis methods that we planned to use in the review as the Mantel-Haenszel method for dichotomous data and the inverse variance method for continuous data, as these methods were not specified in the protocol. We revised the Methods section 'Data synthesis' to reflect these changes.

We were unable to perform the predefined subgroup analyses because identified data were limited, and we reported a post hoc subgroup analysis by degree of baseline UI as performed in the included trial. We updated the Methods section 'Subgroup analysis and investigation of heterogeneity' accordingly.

We were unable to perform a predefined sensitivity analysis according to methodological quality, given the paucity of data. We indicated this in the Methods section 'Sensitivity analysis'.

We moved the description of methods used to rate the quality of evidence and to prepare a 'Summary of findings' table from the Methods section 'Assessment of risk of bias in included studies' to the Methods section "Summary of findings' table'. 